\title{
A study of effects of machining parameters on tool life
}

\author{
Sunday Joshua Ojolo*, Olugbenga Ogunkomaiya \\ Department of Mechanical Engineering, University of Lagos, Akoka-Yaba, Lagos, Nigeria \\ Email address: \\ sojolo@unilag.edu.ng (S. J. Ojolo), olugbengaogunkomaiya@yahoo.com (O. Ogunkomaiya)
}

\section{To cite this article:}

Sunday Joshua Ojolo, Olugbenga Ogunkomaiya. A Study of Effects of Machining Parameters on Tool Life. International Journal of Materials Science and Applications. Vol. 3, No. 5, 2014, pp. 183-199. doi: 10.11648/j.ijmsa.20140305.19

\begin{abstract}
This work involves the investigation carried out to study the effects of machining parameters on tool life under dry machining environment. Three cutting tool materials (HSS blank tool - M2 C66, tungsten carbide insert tool grade P-10, DMNG carbide insert tool 150412-SA) and work materials (medium carbon steel $0.4 \mathrm{wt} \% \mathrm{C}$, mild steel $0.29 \mathrm{wt} \% \mathrm{C}$, brass C330) were examined. The experiments were conducted under three different spindle speeds $(900,1120,1400 \mathrm{rev} / \mathrm{min})$; feed rates $(0.1,0.2,0.3 \mathrm{~mm} / \mathrm{rev})$ and depths of cut $(0.5,1.0,1.5 \mathrm{~mm})$. The settings of machining parameters were determined by using the Taguchi experimental design method. The level of importance of the machining parameters on tool life was determined by using analysis of variance (ANOVA). The optimum machining parameters combination was obtained by using the analysis of signal-to-noise $(\mathrm{S} / \mathrm{N})$ ratio. The relationship between cutting parameters and tool life was obtained. From the results, the spindle speed had the most significant effects on tool life followed by feed rate and the depth of cut. The life of the HSS when cutting the three work pieces (medium carbon steel, mild steel and brass) was 161s, 321s and $386 \mathrm{~s}$ respectively. The life of tungsten carbide when cutting the three work materials was $480 \mathrm{~s}, 726 \mathrm{~s}$ and $1028 \mathrm{~s}$ respectively. The life of DMNG carbide were 782s using medium carbon steel, $864 \mathrm{~s}$ using mild steel, and $1183 \mathrm{~s}$ using brass. The shortest life of the three cutting tool materials (HSS, tungsten carbide and DMNG carbide) on the three work material (medium carbon steel, mild steel and brass) occurred at cutting speed (1400 rev/min), feed rate $(0.3 \mathrm{~mm} / \mathrm{rev})$ and depth of cut $(1.5 \mathrm{~mm})$, where the life of the HSS were (15s using medium carbon steel, $58 \mathrm{~s}$ using mild steel, $94 \mathrm{~s}$ using brass). The life of tungsten carbide were (135s using medium carbon steel, $180 \mathrm{~s}$ using mild steel, $274 \mathrm{~s}$ using brass) and the life of DMNG carbide were ( $219 \mathrm{~s}$ using medium carbon steel, $215 \mathrm{~s}$ using mild steel, $311 \mathrm{~s}$ using brass). The increment of spindle speed, feed rate and depth of cut value mostly will affect the tool life.
\end{abstract}

Keywords: Machining Operation, Cutting Tools, Cutting Conditions, Taguchi Method, ANOVA

\section{Introduction}

An orthogonal metal cutting process for a controlled contact tool is depicted in Figure 1 with labels illustrating the nomenclature used in this paper. An Eulerian reference co-ordinate is used to describe the steady state motion of the workpiece relative to a stationary cutting tool. This cutting method is a common and time favoured metal removal process which produces finished surfaces with high quality. Its general use in all industries may give an impression that it is a perfected art. Yet, tool failure and product quality deterioration account for frequent and costly downtime for all cutting machines. Optimization of the process and accurate estimate of tool life become indispensable in this age of automation.

The goal is to find combinations of these parameters that achieve saving in power consumption, increase in tool life, correct lubrication method (determine tolerable friction condition) and improved surface quality (operate the process away from boundary of stability). The results presented in this work should create the window of optimization for this complicated metal cutting process.

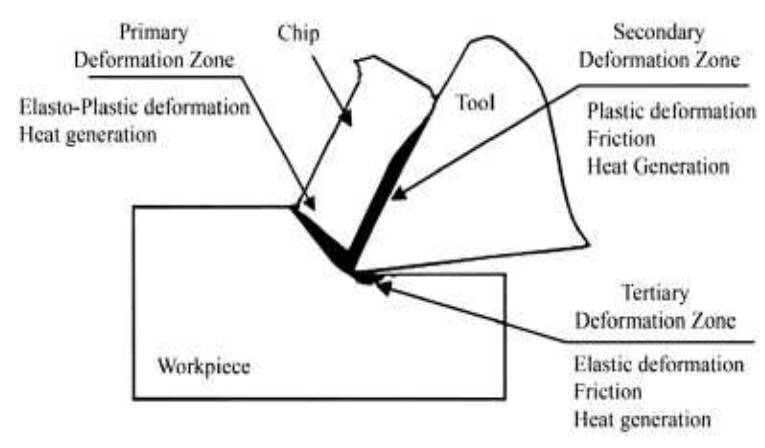

Figure 1. Schematic view of the cutting zone and chip formation [1] 
It has been established experimentally that there is a definite relationship between the cutting speed and tool life; increased cutting speed decreased tool life [2]. Tugrul and Karpat [3] showed that better tool life is obtained in lowest feed rate and lowest cutting speed combination. Most published works on metal cutting regard the cutting speed as having the greatest influence on tool wear and tool life [4].

Astakhov [5] conducted a research using the notion of the optimal cutting temperature and clarify for practical use the influence of the cutting feed, depth of cut, and work-piece (bore) diameter on the tool wear rate. He found out that whenever a cutting operation is done with optimal cutting temperature, increase in the cutting feed leads to an increase in the tool life. He also concluded that an increase in the depth of cut should not change the tool wear rate if the machining is carried out at the optimal cutting regime.

Mohammed et al [6] threw more light into the interactive effect of the process parameters. The result they obtained showed that the most important interactions, that effected surface roughness of machined surfaces, were between the cutting feed and depth of cut, and between cutting feed and spindle speed. They also concluded that cutting feed is by far the most dominant factor on surface roughness.

The two tool parameters having an influence on tool life are tool geometry and tool material. The standard single point tool geometry affecting tool life are nose radius, end cutting edge angle, side cutting edge angle, side rake angle, side relief angle, back rake angle and back relief angle. Of the seven factors describing tool geometry, the three having the most pronounced effect on tool life are the side rake angle, the side cutting edge angle, and the nose radius [7].

Ojolo et al [8] investigated the possibility of using biological oil (palm kernel, groundnut oil, shea butter and coconut oil) with respect to cutting force, during cylindrical turning of mild steel, aluminum and copper rods. The result of the experiment clearly indicated that bio oils are suitable for metal cutting fluids during machining operation. They also concluded that groundnut and palm kernel oils are effective in reducing cutting force and increasing tool life during cylindrical turning.

Kadirgama et al [9] conducted a research on the effect of dry cutting on cutting force and tool life and made a general comparison between the experiments carried out with cutting fluid and without using any coolant and lubricant. The result showed that dry cutting produce high cutting force and low tool life compared with using coolant. They also discovered that most of the cutting tool from the dry cutting suffered high crack and some insert damage.

Work-piece microstructure has a correlation with the life of a cutting tool. In general, any constituents in the work-piece microstructure which are harder than the tool material tend to decrease tool life. For example, hard insoluble particles of aluminum oxide in the work-piece structure decrease tool life because of their abrasive action on the tool face. Conversely, some types of softer particles such as manganese sulfide in steel and lead in steel and brass have a very beneficial effect on tool life. It is believed these particles decrease the tendency for localized pressure welding to take place at the tool-chip or tool-workpiece interface, thereby creating better machined surfaces and longer tool life [7].

Taguchi method is used for the turning process by optimizing the process parameters. Optimization of process parameters is the key step in the Taguchi method to achieving high quality without increasing cost. This is because optimization of process parameters can improve quality and the optimal process parameters obtained from the Taguchi method are insensitive to the variation of environmental conditions and other noise factors. Basically, classical process parameter design is complex and not easy to use [10]. An advantage of the Taguchi method is that it emphasizes a mean performance characteristic value close to the target value rather than a value within certain specification limits, thus improving the product quality. Additionally, Taguchi's method for experimental design is straightforward and easy to apply to many engineering situations, making it a powerful yet simple tool. It can be used to quickly narrow the scope of a research project or to identify problems in a manufacturing process from data already in existence $[11,12]$.

In general, the parameter optimization process of the Taguchi method is based on 8-steps of planning, conducting and evaluating results of matrix experiments to determine the best levels of control parameters [13]. The experimental confirmation test is the final step in verifying the results drawn based on Taguchi's design approach. The optimal conditions are set for the significant factors (the insignificant factors are set at economic levels) and a selected number of experiments are run under specified cutting conditions. The average of the results from the confirmation experiment is compared with the predicted average based on the parameters and levels tested. The confirmation experiment is a crucial step and is highly recommended by Taguchi to verify the experimental results [14].

Many studies have been made using Taguchi Method to optimize the turning parameter. Nalbant et al [15] use $\mathrm{L}_{9}(3)^{4}$ orthogonal array, signal-to-noise ratio and analysis of variance to study the performance characteristics in turning operations of AISI 1030 steel bars using P20 grade tin coated cutting inserts types with TNMG160404-MA, TNMG160408-MA and TNMG160412-MA. Three cutting parameters namely, insert radius, feed rate, and depth of cut, are optimized with considerations of surface roughness. The experimental results demonstrated that the insert radius and feed rate are the main parameters among the three controllable factors (insert radius, feed rate and depth of cut) that influence the surface roughness in turning AISI 1030 carbon steel.

Yang and Tarng [16] carried out an experiment consist of eighteen combinations on an engine lathe using tungsten carbide grade $\mathrm{P} 10$ for the machining of S45C steel bars. The cutting parameters that were been selected are cutting speed, feed rate and depth of cut with the response variable, tool life and surface roughness. Result showed that cutting speed and 
feed rate are the significant cutting parameters that affect tool life, while the change of the depth of cut in the range has an insignificant effect on tool life. For surface roughness, all the cutting parameters have the significant effect. The confirmation experiments were conducted to verify the optimal cutting parameters. The improvement of tool life and surface roughness from the initial cutting parameters to the optimal cutting parameters was about $250 \%$.

Mahapatra et al [17] applied Taguchi design concept to determine the influence of the cutting velocity, feed rate and depth of cut on surface roughness and tool life. Their experiments confirmed that cutting velocity and feed rate have greater influence on the surface roughness and tool life. This result also confirmed that the interaction between cutting velocity and feed rate has a significant effect on surface roughness while the interaction between cutting velocity and feed rate, and cutting velocity and depth of cut has greater significant on tool life.

Mathematical modeling in terms of process parameters for tool life has been carried out by many researchers. Kaye et al [18] developed a mathematical model based on response surface methodology to predict tool flank wear using spindle speed change. The grey-Taguchi method was adopted to optimize the milling parameters of aluminum alloy with multiple performance characteristics and they found that flank wear decreased from $0.177 \mathrm{~mm}$ to 0.067 mm. Manna and Salodkar [19] conducted an experiment to investigate the effect of machining parameters on surface roughness during turning of E0300 alloy steel, using DNMG15608EF grade 8030 as the single point cutting tool material. The result showed that cutting speed is the most effecting parameter on surface roughness compare to feed and depth of cut. Sivasakthivel et al [20] developed mathematical model using central composite rotatable second order response methodology to predict the adequacy of the tool wear using ANOVA in terms of machining parameters such as helix angle of cutting tool, spindle speed, feed rate, axial and radial depth of cut. Their result showed that the helix angle is the most significant parameter which reduces tool wear. They also found out that increase in spindle speed and axial depth of cut reduces tool wear. They further analyzed the interactions between process parameters and strong interactions were observed between helix angle and axial depth of cut, spindle speed and feed rate, helix angle and feed rate, and spindle speed and radial depth of cut.

Kartal [21] has employed an orthogonal array of $\mathrm{L}_{9}$ (3), the signal-to-noise ratio $(\mathrm{S} / \mathrm{N})$ and the analysis of variance (ANOVA) to investigate the cutting characteristics of St 33 and St 52 steel bars using hard mine tipped pen cutting tool in CNC turning operation. Controlled factors were cutting speed $(120 \mathrm{~m} / \mathrm{min}, 150 \mathrm{~m} / \mathrm{min}, 180 \mathrm{~m} / \mathrm{min})$, feed-rate $(0.1$ $\mathrm{mm} / \mathrm{rev}, 0.2 \mathrm{~mm} / \mathrm{rev}, 0.3 \mathrm{~mm} / \mathrm{rev})$ and depth of cut $(0.5 \mathrm{~mm}$, $1.0 \mathrm{~mm}, 1.5 \mathrm{~mm})$. Performance characteristics were amount of tool wear and surface roughness. After analyzing the collected data, it was found out that cutting speed is most effective parameter for tool life and feed-rate has a smaller effect compared with cutting speed. The most effective parameter is feed-rate for surface roughness; cutting speed and depth of cut have smaller effects when compared with feed-rate.

\section{Materials and Methods}

\subsection{Materials}

The materials used for this research work are Lathe machine Heidenreich \& Harbeck- Hamburg 250, HSS cutting tool $(14 \times 14 \times 200$ HSS-M2 C66), tungsten carbide grade P-10, DMNG carbide tool, Vernier caliper, tape rule, medium carbon steel diameter $50 \mathrm{~mm} \times 1200 \mathrm{~mm}$ long, mild steel and brass, diameter $50 \mathrm{~mm} \times 1400 \mathrm{~mm}$ long respectively. The HSS and Tungsten carbide were purchased from Agarawu Market, Lagos Island while the DNMG carbide tool was obtained from the company where the experiments were carried out.

The following process parameters were used:

(1) Lathe spindle feed, IPR (inch/1000 $\times 1 /$ rev) of 5,8 and $12 \mathrm{inch} / \mathrm{rev}$

(2) Spindle speed of $900 \mathrm{rev} / \mathrm{min}, 1120 \mathrm{rev} / \mathrm{min}$ and 1400rev/min

(3) Feed rate of $0.1 \mathrm{~mm} / \mathrm{rev}, 0.2 \mathrm{~mm} / \mathrm{rev}$ and $0.3 \mathrm{~mm} / \mathrm{rev}$

(4) Depth of cut of $0.5 \mathrm{~mm}, 1.0 \mathrm{~mm}$ and $1.5 \mathrm{~mm}$

(5) Clearance angle of $11^{\circ}$ and rake angle of $0^{\circ}$

(6) The turning operation was carried out without lubricant.

(7) The spindle speed and feed rate were varied according to the value selected above while the depth of cut remained constant at $0.5 \mathrm{~mm}, 1.0 \mathrm{~mm}$ and $1.5 \mathrm{~mm}$.

\subsection{Experimental Procedure}

A Lathe machine Heidenreich \& Harbeck- Hamburg 250 with a spindle speed range from 900 to $1400 \mathrm{rpm}$ was used for the machining trial. The machining center was driven by $5.5 \mathrm{~kW}$ electric motor. The experiment was done under dry machining environment. A tape rule model Fat Max Blade Armor $35^{\prime}$ was used to measure the total cutting length a tool will cut effectively. Tool life was determined by dividing the total length of effective cut by the product of feed rate and spindle speed of machining. The same machine was used for all experimental work. The tool life data were collected for each of the cutting conditions. Table 1 presents the cutting parameters.

Table 1. The cutting parameters and their levels

\begin{tabular}{lllll}
\hline \multirow{2}{*}{ Symbol } & Parameters & \multicolumn{2}{l}{ Level } & \\
\cline { 3 - 5 } & & $\mathbf{1}$ & $\mathbf{2}$ & $\mathbf{3}$ \\
\hline A & Spindle speed N, rev/min & 900 & 1120 & 1400 \\
B & Feed rate f, mm/rev & 0.1 & 0.2 & 0.3 \\
C & Depth of cut d, mm & 0.5 & 1.0 & 1.5 \\
\hline
\end{tabular}




\subsubsection{Calculation of Feed Rate}

The feed rate $f$, was calculated from

$$
\text { Feed rate in } m m P R=\frac{24.5 \times I P R}{1000}
$$

Where,

$\mathrm{IPR}=$ Feed rate in inch per revolution $\mathrm{mmPR}=$ Feed rate in mmillimeter per revolution

\subsubsection{Calculation of Tool Life}

The tool life is estimated from

$$
\begin{gathered}
\mathrm{RPM} \times m m \mathrm{PR}=m m \mathrm{PM} \\
T=L \times 60 / m m P M
\end{gathered}
$$

Where,

$\mathrm{RPM}=$ Revolution per minute

$\mathrm{mmPR}=$ Millimeter per revolution

$\mathrm{L}=$ Length of effective cut

$\mathrm{T}=$ Tool life in second

\section{Results and Discussion}

The results of the experiments are presented in Figures 2-10 and Table 2

\subsection{Medium Carbon Steel}

Figure 2 show the effect of spindle speeds of 900, 1120, $1400 \mathrm{rev} / \mathrm{min}$ on life of tools for all values of the feed rate of $0.1,0.2,0.3 \mathrm{~mm} / \mathrm{rev}$. As the spindle speed increased from $900 \mathrm{rev} / \mathrm{min}$ up to $1400 \mathrm{rev} / \mathrm{min}$, the tool life of HSS tool reduced from $161 \mathrm{~s}$ to $52 \mathrm{~s}$, approximately $68 \%$ reduction in tool life at constant feed of $0.1 \mathrm{~mm} / \mathrm{rev}$. It can be seen that better tool life is obtained with a combination of spindle speed 900rev/min and feed $0.1 \mathrm{~mm} / \mathrm{rev}$. This agrees with Tugrul and Karpat [3], which had earlier discovered that better tool life is obtained in lowest feed rate and lowest cutting speed combination. The same trend was observed at feed rate of 0.2 $\mathrm{mm} / \mathrm{rev}$. As the spindle speed increased from $900 \mathrm{rev} / \mathrm{min}$ to $1400 \mathrm{~mm} / \mathrm{rev}$, the tool life of HSS drastically reduced from $128 \mathrm{~s}$ to $27 \mathrm{~s}$ i.e. $79 \%$ reduction. This showed that as the spindle speed increases, the cutting temperature increases. As a result of this, the tool experienced larger chip loads that caused more intensive wear. At $0.3 \mathrm{~mm} / \mathrm{rev}$ feed rate, the tool life of HSS tool decreased dramatically from $107 \mathrm{~s}$ to $15 \mathrm{~s}$, approximately $86 \%$ reduction as the spindle speed increased. This is traced to a high amount of carbon in medium carbon steel; at elevated temperature a brittle fracture occurs at the cutting edge and the depth of the cracks on the cutting edge increases rapidly resulting in a catastrophic fracture of the tool. This is similar to what was obtained by [2]. The same trends that occur in the tool life of HSS were observed in tungsten carbide tool but with higher tool life. When spindle speed was increased from $900 \mathrm{rev} / \mathrm{min}$ to $1400 \mathrm{rev} / \mathrm{min}$ for all values of the feed rate of $0.1,0.2,0.3 \mathrm{~mm} / \mathrm{rev}$ (Table 2), the tool life of tungsten carbide decreased from 400 s to $167 \mathrm{~s}$. This is due to its high wear resistance. At constant feed of $0.1 \mathrm{~mm} / \mathrm{rev}$ and spindle speed of 900rev/min, the tool life of tungsten carbide was 480 s which indicate longer tool life. When the spindle speed was increased to $1400 \mathrm{rev} / \mathrm{min}$ under the same conditions, the tool life decreased to 229 s i.e. $53 \%$ reduction. As the spindle speed increased at constant feed of $0.2 \mathrm{~mm} / \mathrm{rev}$ the tool life of tungsten carbide decreased from 400 s to $167 \mathrm{~s}$, approximately 59\% reduction in tool life. This is because cutting force on the tool edge increased as the spindle speed increased. Though carbide tools have high hot hardness and wear resistance, they have low fracture toughness. As a result, tool wear intensifies at a high cutting speed. The same trend was observed when feed rate is constant at $0.3 \mathrm{~mm} / \mathrm{rev}$; tool life of tungsten carbide decreased from $357 \mathrm{~s}$ to $135 \mathrm{~s}$ as the spindle speed increased. The useful life of cutting tool is drastically reduced when it is applied to machining of hardened steel, especially, in the high-speed range [22]. When using DMNG tool at varying speeds; the percentage reduction of the tool life was lower compare to other tool materials. As the spindle speed increased from $900 \mathrm{rev} / \mathrm{min}$ to $1400 \mathrm{rev} / \mathrm{min}$ at constant feed of $0.1 \mathrm{~mm} / \mathrm{rev}$, the tool life decreased from 782 s to 373 s given a $52 \%$ reduction. The same trend occurred when feed was constant at $0.2 \mathrm{~mm} / \mathrm{rev}$; tool life of DMNG decreased from 650 s to 284 s given a $56 \%$ reduction as the spindle speed increased from $900 \mathrm{rev} / \mathrm{min}$ to $1400 \mathrm{rev} / \mathrm{min}$. Also at constant feed rate of $0.3 \mathrm{~mm} / \mathrm{rev}$ the tool life decreased from $567 \mathrm{~s}$ to $219 \mathrm{~s}$ as the spindle speed increased from $900 \mathrm{rev} / \mathrm{min}$ to $1400 \mathrm{rev} / \mathrm{min}$. This can be explained that varying the spindle speed at high level aggravates tool wear which will excessively lead to shorter tool life.

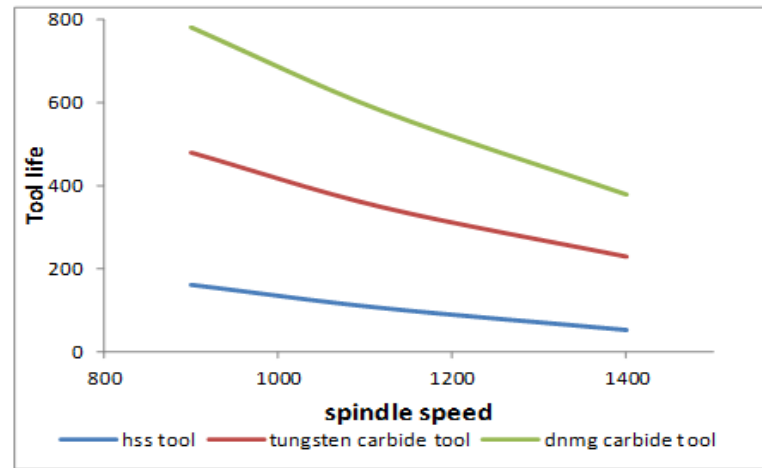

Figure 2a. Effect of spindle speed on life of tools at constant feed rate of $0.1 \mathrm{~mm} / \mathrm{rev}$

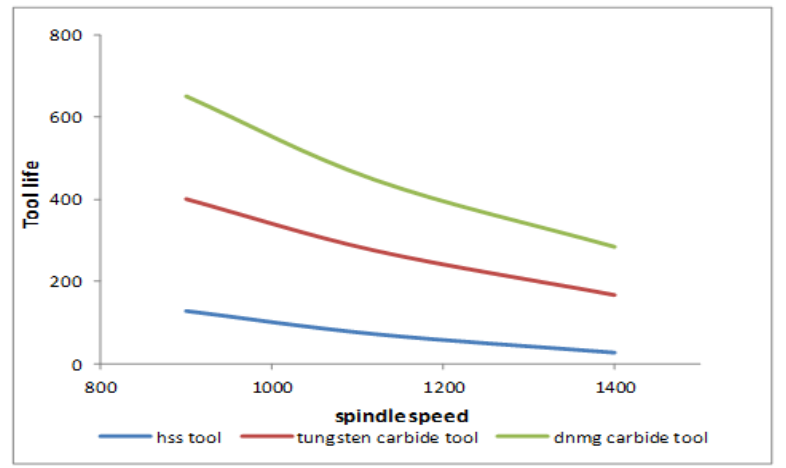

Figure 2b. Effect of spindle speed on life of tools at constant feed rate of 0.2 $\mathrm{mm} / \mathrm{rev}$ 


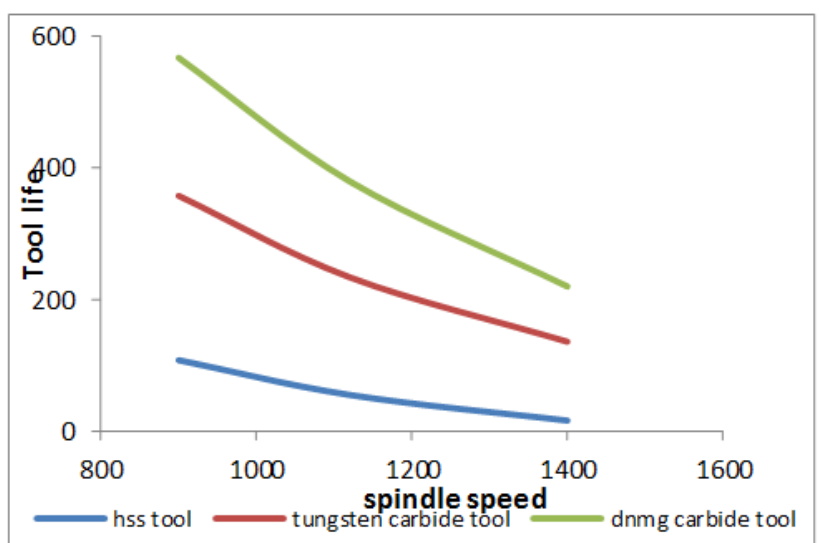

Figure 2c. Effect of spindle speed on life of tools at constant feed rate of 0.3 $\mathrm{mm} / \mathrm{rev}$

Figure 3 show the effect of feed rate $(0.1,0.2,0.3 \mathrm{~mm} / \mathrm{rev})$ on life of tools for all values of the spindle speeds $(900,1120$, $1400 \mathrm{rev} / \mathrm{min}$ ). As the feed rate increased from $0.1 \mathrm{~mm} / \mathrm{rev}$ up to $0.3 \mathrm{~mm} / \mathrm{rev}$, the tool life of HSS reduced from $161 \mathrm{~s}$ to $107 \mathrm{~s}$, approximately $34 \%$ reduction in tool life at constant spindle speed $900 \mathrm{rev} / \mathrm{min}$. The same trend was observed at spindle speed $1120 \mathrm{rev} / \mathrm{min}$, as the feed rate increased from $0.1 \mathrm{~mm} / \mathrm{rev}$ to $0.3 \mathrm{~mm} / \mathrm{rev}$ (Table 2). The tool life of HSS reduced from $105 \mathrm{~s}$ to $54 \mathrm{~s}$ i.e. $49 \%$ reduction. It can be seen that percentage reduction in the HSS tool increased from $34 \%$ to $49 \%$ which attributed to the fact that increased feed rate led to a corresponding change in temperature, leading to shorter tool life. But if low speed is used the cutting temperature will be lower than the optimal cutting temperature, leading to longer tool life i.e. an increase in the cutting feed lead to a decrease in tool life, this agrees with Astakhov [5]. The decreasing trend occurs due to more wear occurring on the cutting edge at the higher spindle speed of $1400 \mathrm{rev} / \mathrm{min}$. As the feed rate increased up to $0.3 \mathrm{~mm} / \mathrm{rev}$, the tool life of HSS decreased from $52 \mathrm{~s}$ to $15 \mathrm{~s}$ by $72 \%$. The reason might be due to increase in feed rate that causes the bigger interface between cutting tool and work-piece. Larger contact area, resulted in more friction that caused more heat generated, consequently shorten the tool life. When using tungsten carbide tool it was observed that at constant spindle speed of $900 \mathrm{rev} / \mathrm{min}$ the tool life of tungsten carbide decreased from $480 \mathrm{~s}$ to $357 \mathrm{~s}$ as the feed vary from $0.1 \mathrm{~mm}$ /rev to $0.3 \mathrm{~mm} / \mathrm{rev}$ showing $26 \%$ reduction in tool life. At a spindle speed of $1120 \mathrm{rev} / \mathrm{min}$, there was a decrease in the tool life of tungsten carbide from 384 s to 233 s i.e. $39 \%$ reduction as the feed rate vary from $0.1 \mathrm{~mm} / \mathrm{rev}$ to $0.3 \mathrm{~mm} / \mathrm{rev}$, this agrees with [23] that, if the cutting speed and depth of cut are both constant, then the tool life decreased when the cutting feed is increased. The same trend was observed at constant spindle speed of $1400 \mathrm{rev} / \mathrm{min}$, as the feed rate increased from $0.1 \mathrm{~mm} / \mathrm{rev}$ to $0.3 \mathrm{~mm} / \mathrm{rev}$. The tool life of tungsten carbide reduced from $229 \mathrm{~s}$ to $135 \mathrm{~s}$ with $41 \%$ reduction. At these conditions, the effect of feeding at 0.3 $\mathrm{mm} / \mathrm{rev}$ is clear on tool life giving shorter tool life in all cases. However, this phenomenon can be attributed to the fact that increased feed rate, reduced tool life but actually increased the amount of material that could be removed by the tool. When using DMNG tool at varying feed the percentage reduction of the tool was lower compare to other tool materials. The tool life of DMNG at constant spindle speed of $900 \mathrm{rev} / \mathrm{min}$ decreased from $782 \mathrm{~s}$ to $567 \mathrm{~s}$ as the feed rate increased from $0.1 \mathrm{~mm} / \mathrm{rev}$ to $0.3 \mathrm{~mm} / \mathrm{rev}$ given a $27 \%$ reduction. As the spindle speed increased to $1120 \mathrm{rev} / \mathrm{min}$ under the same conditions; lower values of tool life 580 s to 379 s were obtained given a percentage reduction of $35 \%$. This is similar to $307 \mathrm{~min}$ to $76 \mathrm{~min}$ obtained by Zhou et al [24] at cutting speed of $66.88 \mathrm{~m} / \mathrm{min}$ and $94.2 \mathrm{~m} / \mathrm{min}$ for cemented low carbon alloy steel using high hardness cutting tool of tungsten carbide. The same trend was observed at constant spindle speed of $1400 \mathrm{rev} / \mathrm{min}$; the tool life of DMNG decreased from 373 s to 219 s as the feed rate varying from $0.1 \mathrm{~mm} / \mathrm{rev}$ to $0.3 \mathrm{~mm} / \mathrm{rev}$. This happened because varying the feed rate at high level aggravates tool wear which will excessively lead to shorter tool life. Hence it can be deduced that the useful life of cutting tool is drastically reduced when it is applied to machining of hardened steel which had earlier reported that the higher the hardness of the workpiece material, the lower is the life of the cutter [25].

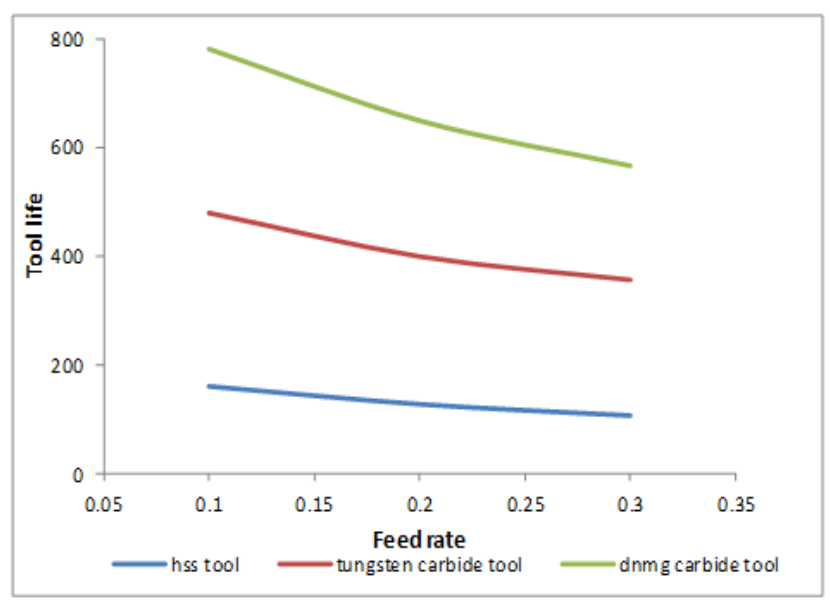

Figure 3a. Effect of feed rate on life of tools at constant spindle speed of $900 \mathrm{rev} / \mathrm{min}$

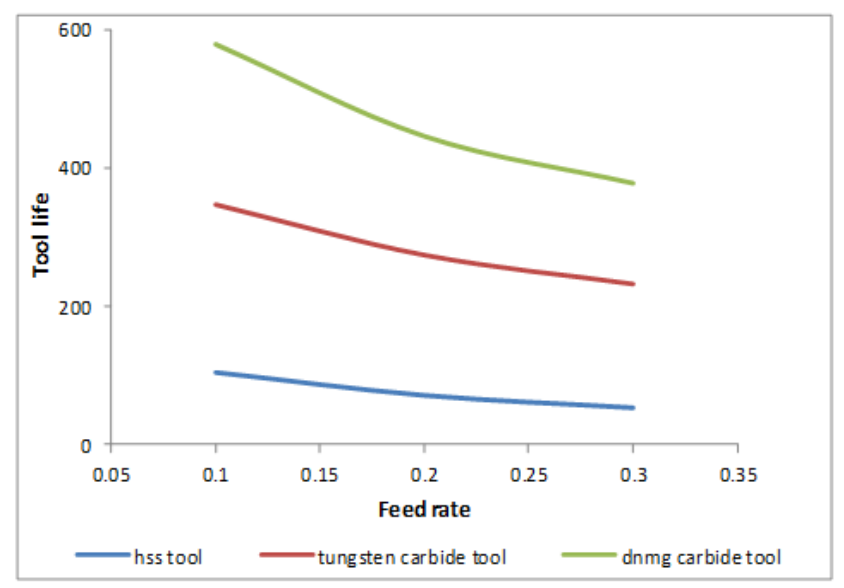

Figure $3 \boldsymbol{b}$. Effect of feed rate on life of tools at constant spindle speed of $1120 \mathrm{rev} / \mathrm{min}$ 


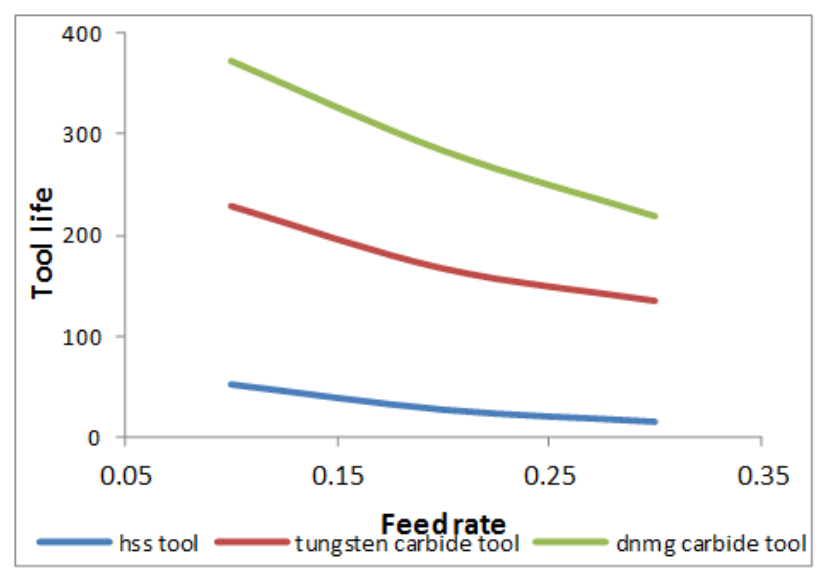

Figure 3c. Effect of feed rate on life of tools at constant speed of 1400 $\mathrm{rev} / \mathrm{min}$

Figure 4 show the effect of depth of cut $(0.5,1.0,1.5 \mathrm{~mm})$ on life of tools for all values of the spindle speeds $(900,1120$, $1400 \mathrm{~mm} / \mathrm{rev}$ ). As the depth of cut increased from 0.5 to $1.5 \mathrm{~mm}$, the tool life of HSS reduced from 161s to $107 \mathrm{~s}$ at constant spindle speed $900 \mathrm{rev} / \mathrm{min}$. This is as a result of lower spindle speed that cannot enhance increase in cutting force at the cutting zone as the depth of cut increases. More materials will have to be cut which means more energy will be required and this will cause an increase in the cutting force and hence, decrease tool life. The same trend was observed at spindle speed $1120 \mathrm{rev} / \mathrm{min}$, as the depth of cut increased from $0.5 \mathrm{~mm}$ to $1.5 \mathrm{~mm}$ the contact length of the cutting edge with the work-piece increases and wear occurs deeper along the cutting edge as the tool life of HSS reduced from 105 s to $54 \mathrm{~s}$ i.e. $49 \%$ reduction. At spindle speed of $1400 \mathrm{rev} / \mathrm{min}$, increased depth of cut up to $1.5 \mathrm{~mm}$ led to a corresponding increase in chip width. The center of pressure of the chip on the tool face moves away from the tool nose, causing a decreased in the tool life from 52 s to 15 s i.e. $72 \%$. When using tungsten carbide tool it was observed that at constant spindle speed of $900 \mathrm{rev} / \mathrm{min}$ the tool life of tungsten carbide decreased from $480 \mathrm{~s}$ to $357 \mathrm{~s}$ as the depth of cut varied from $0.5 \mathrm{~mm}$ to $1.5 \mathrm{~mm}$ showing $26 \%$ reduction in tool life. At a spindle speed of $1120 \mathrm{rev} / \mathrm{min}$, there is a decrease in the tool life of tungsten carbide from $384 \mathrm{~s}$ to 233 s i.e. $39 \%$ reduction. The same trend was observed at constant spindle speed of $1400 \mathrm{rev} / \mathrm{min}$, increased depth of cut up to $1.5 \mathrm{~mm}$ caused more compressive stress on the cutting edge resulting in rapid fracture of the tool thereby resulting in decreased life from $229 \mathrm{~s}$ to $135 \mathrm{~s}$. At these conditions, the effect of depth of cut at $1.5 \mathrm{~mm}$ was evident on tool life giving shorter tool life in all cases. However, this phenomenon can be attributed to the fact that increased depth of cut reduced tool life but actually increased the amount of material that could be removed by the tool. When using DMNG tool at a varying depth of cut the percentage reduction in the tool was lower compared to other tool materials. The tool life of DMNG at constant spindle speed of $900 \mathrm{rev} / \mathrm{min}$ decreased from $782 \mathrm{~s}$ to $567 \mathrm{~s}$ as the depth of cut increased from $0.5 \mathrm{~mm}$ to $1.5 \mathrm{~mm}$. As the spindle speed increased to $1120 \mathrm{rev} / \mathrm{min}$ under the same conditions, lower values of tool life (580s to 379 s) were obtained. The same trend was observed at constant spindle speed of $1400 \mathrm{rev} / \mathrm{min}$ the tool life of DMNG decreased from 373s to $219 \mathrm{~s}$ as the depth of cut vary from $0.5 \mathrm{~mm}$ to $1.5 \mathrm{~mm}$. This occurred because varying the depth of cut at high level aggravates tool wear which will excessively lead to shorter tool life.

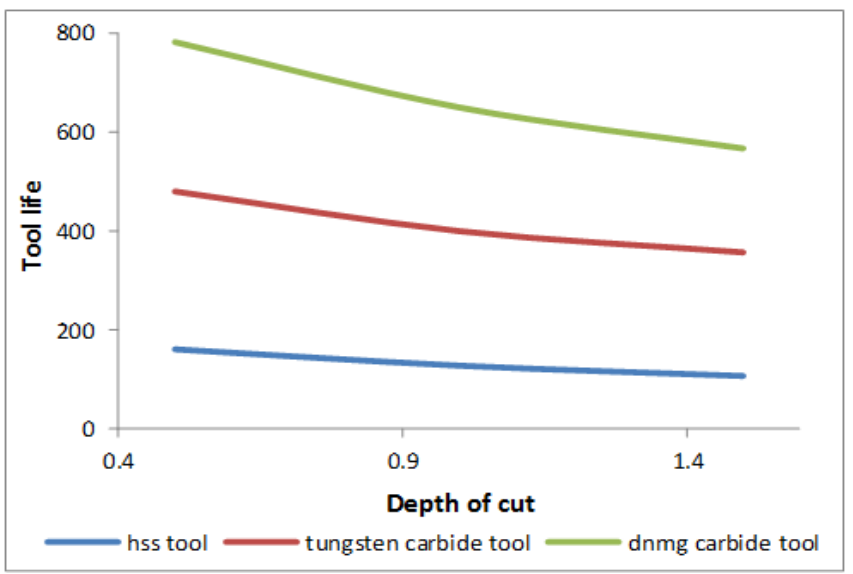

Figure 4a. Effect of depth of cut on life of tools at constant spindle speed of $900 \mathrm{rev} / \mathrm{min}$

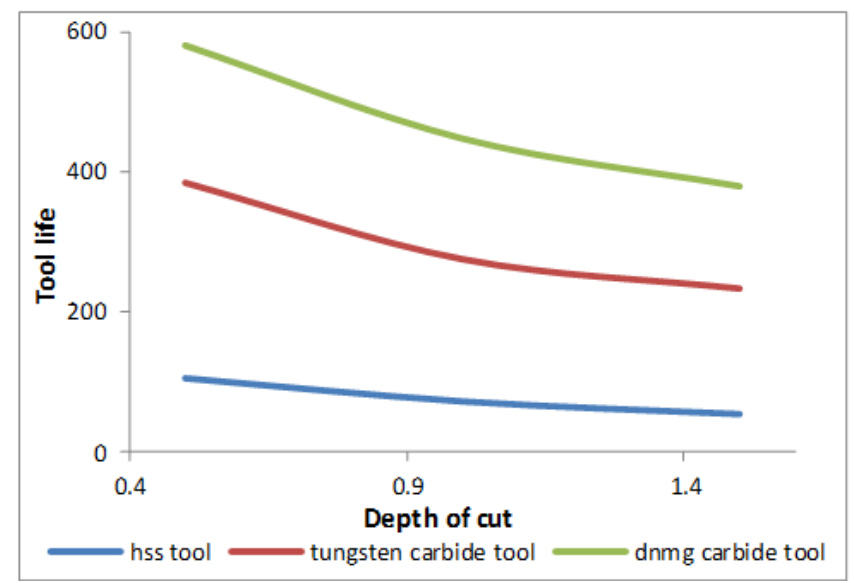

Figure 4b. Effect of depth of cut on life of tools at constant spindle speed of $1120 \mathrm{rev} / \mathrm{min}$

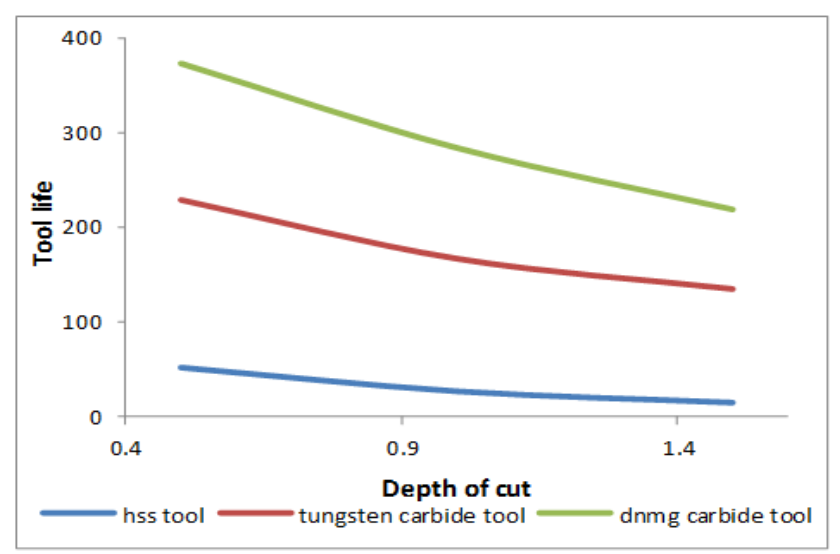

Figure 4c. Effect of depth of cut on life of tools at constant spindle speed of $1400 \mathrm{rev} / \mathrm{min}$ 


\subsection{Mild Steel}

Figure 5 show the effect of spindle speed $(900,1120,1400$ $\mathrm{rev} / \mathrm{min})$ on life of tools for all values of the feed rate $(0.1$, $0.2,0.3 \mathrm{~mm} / \mathrm{rev}$ ). As the spindle speed increased from $900 \mathrm{rev} / \mathrm{min}$ up to $1400 \mathrm{rev} / \mathrm{min}$, the life of HSS tool reduced from $321 \mathrm{~s}$ to $124 \mathrm{~s}$ i.e $61 \%$ reduction at constant feed 0.1 $\mathrm{mm} / \mathrm{rev}$. It can be seen that better tool life was obtained with a combination of spindle speed $900 \mathrm{rev} / \mathrm{min}$ and feed $0.1 \mathrm{~mm} / \mathrm{rev}$. This agrees with Khan et al [26] that the life of cutting tools is very long while machining with low cutting parameters. At low cutting parameters a gradual flank wear was observed. The same decreasing trend was observed, as the spindle speed increased from $900 \mathrm{rev} / \mathrm{min}$ to $1400 \mathrm{rev} / \mathrm{min}$ at constant feed of $0.2 \mathrm{~mm} / \mathrm{rev}$. A brittle fracture occurs at the cutting edge rather than a gradual flank wear and the depth of the cracks on the cutting edge increased rapidly resulting in a catastrophic failure of the tool. At $0.3 \mathrm{~mm} / \mathrm{rev}$ feed rate, the life of HSS tool decreased dramatically from $224 \mathrm{~s}$ to $58 \mathrm{~s}$ as the spindle speed increased. This is similar to the results obtained by Alauddin et al [27]. The same trends that occured in the tool life of HSS were observed in tungsten carbide tool but with higher tool life. When spindle speed was increased from $900 \mathrm{rev} / \mathrm{min}$ to $1400 \mathrm{rev} / \mathrm{min}$ for all values of the feed rate $(0.1,0.2,0.3 \mathrm{~mm} / \mathrm{rev})$, the tool life of tungsten carbide decreased. At constant feed of $0.1 \mathrm{~mm} / \mathrm{rev}$, the tool life of tungsten carbide decreased from $726 \mathrm{~s}$ to $320 \mathrm{~s}$ i.e. $56 \%$ reduction. When spindle speed was increased at constant feed of $0.2 \mathrm{~mm} / \mathrm{rev}$, the tool life of tungsten carbide decreased from $589 \mathrm{~s}$ to $242 \mathrm{~s}$. This is because cutting force on the tool edge increased as the spindle speed increased. Though carbide tools have high hot hardness and wear resistance, they have low fracture toughness. As a result tool wear intensifies at a high cutting speed. The same trend occurred when feed rate was constant at $0.3 \mathrm{~mm} / \mathrm{rev}$, tool life of tungsten carbide decreased from 541s to $180 \mathrm{~s}$ as the spindle speed increased i.e. $67 \%$ reduction. This occurred because at high feed rate, increase in the spindle speed may cause vibration in the system which resulted in shorter tool life. When using DMNG tool at a varying speed the percentage reduction of the tool was lower compare to other tool materials. As the spindle speed increases from $900 \mathrm{rev} / \mathrm{min}$ to $1400 \mathrm{rev} / \mathrm{min}$ at constant feed of $0.1 \mathrm{~mm} / \mathrm{rev}$, the tool life decreased from $864 \mathrm{~s}$ to $381 \mathrm{~s}$. The same trend was observed when feed was constant at $0.2 \mathrm{~mm} / \mathrm{rev}$, tool life of DMNG decreased from $702 \mathrm{~s}$ to $283 \mathrm{~s}$ as the spindle speed increased from $900 \mathrm{rev} / \mathrm{min}$ to $1400 \mathrm{rev} / \mathrm{min}$. Also at constant feed rate of $0.3 \mathrm{~mm} / \mathrm{rev}$ the tool life decreased from $644 \mathrm{~s}$ to $215 \mathrm{~s}$ as the spindle speed vary from $900 \mathrm{rev} / \mathrm{min}$ to 1400 $\mathrm{rev} / \mathrm{min}$. This occurred because varying the spindle speed at high level aggravates tool wear which will excessively lead to shorter tool life.

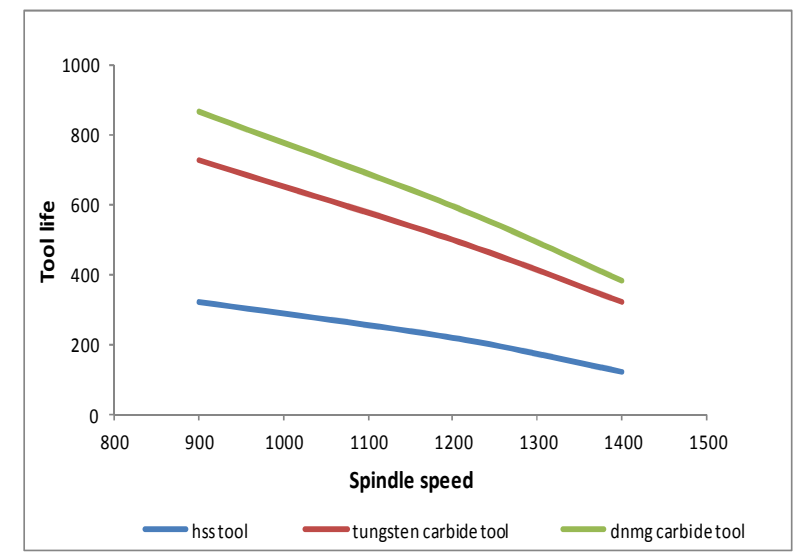

Figure 5a. Effect of spindle speed on life of tools at constant feed rate of 0.1 $\mathrm{mm} / \mathrm{rev}$

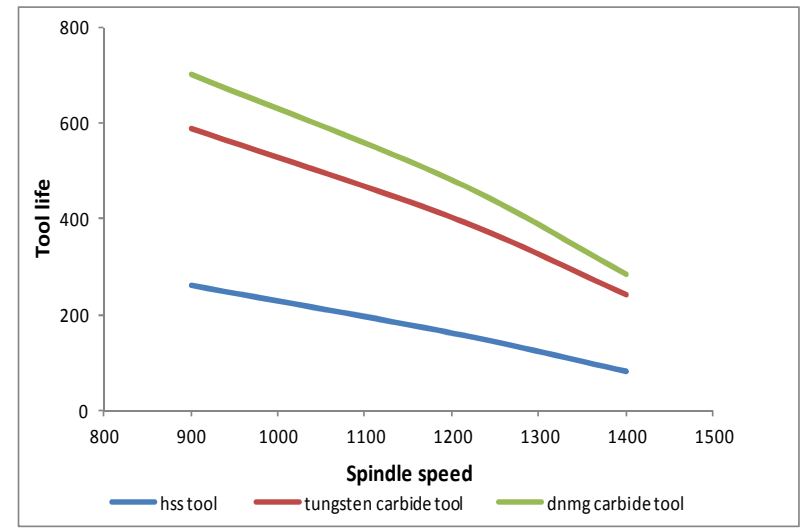

Figure 5b. Effect of spindle speed on life of tools at constant feed rate of 0.2 $\mathrm{mm} / \mathrm{rev}$

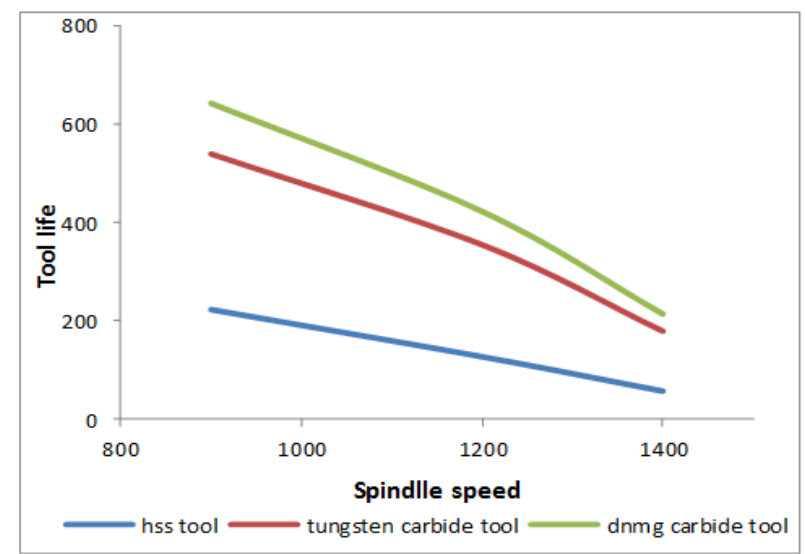

Figure 5c. Effect of spindle speed on life of tools at constant feed rate of 0.3 $\mathrm{mm} / \mathrm{rev}$

Figure 6 show the effect of feed rate $(0.1,0.2,0.3 \mathrm{~mm} / \mathrm{rev})$ on life of tools for all values of the spindle speed $(900,1120$, $1400 \mathrm{rev} / \mathrm{min}$ ). As the feed rate increased from $0.1 \mathrm{~mm} / \mathrm{rev}$ to $0.3 \mathrm{~mm} / \mathrm{rev}$ at constant spindle speed of $900 \mathrm{rev} / \mathrm{min}$, the tool life of HSS, tungsten carbide and DMNG carbide reduced from $321 \mathrm{~s}$ to $224 \mathrm{~s}, 726 \mathrm{~s}$ to $541 \mathrm{~s}$ and $864 \mathrm{~s}$ to $644 \mathrm{~s}$ respectively. This happened because varying the feed rate at high level aggravates tool wear which will excessively lead 
to shorter tool life. The same trend was observed at constant spindle speed of $1120 \mathrm{rev} / \mathrm{min}$ as the feed rate increased from $0.1 \mathrm{~mm} / \mathrm{rev}$ to $0.3 \mathrm{~mm} / \mathrm{rev}$. At constant spindle speed of $1400 \mathrm{rev} / \mathrm{min}$, more wear occurs on the cutting edges as the feed rate increased from $0.1 \mathrm{~mm} / \mathrm{rev}$ to $0.3 \mathrm{~mm} / \mathrm{rev}$. The tool life of HSS, tungsten carbide and DMNG carbide decreased from 124 s to $58 \mathrm{~s}, 320$ s to 180 s and 381 s to 215 s respectively. This happened because increased feed rate with high value of spindle speed reduced tool life but actually increased the amount of material that could be removed by the tool.

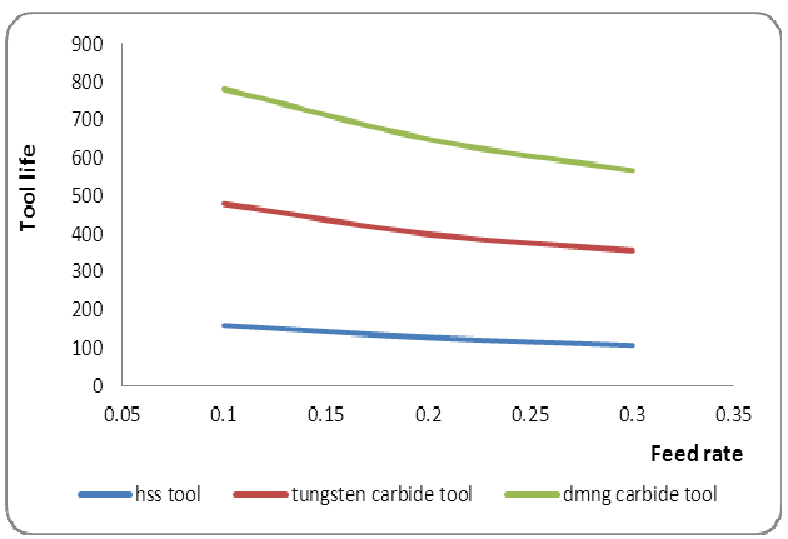

Figure 6a. Effect of feed rate on life of tools at constant spindle speed of $900 \mathrm{rev} / \mathrm{min}$

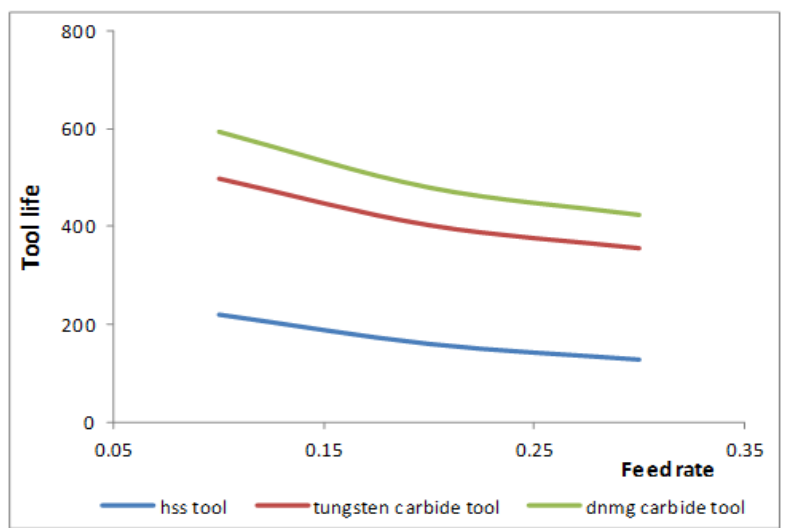

Figure 6b. Effect of feed rate on life of tool at constant spindle speed of $1400 \mathrm{rev} / \mathrm{min}$

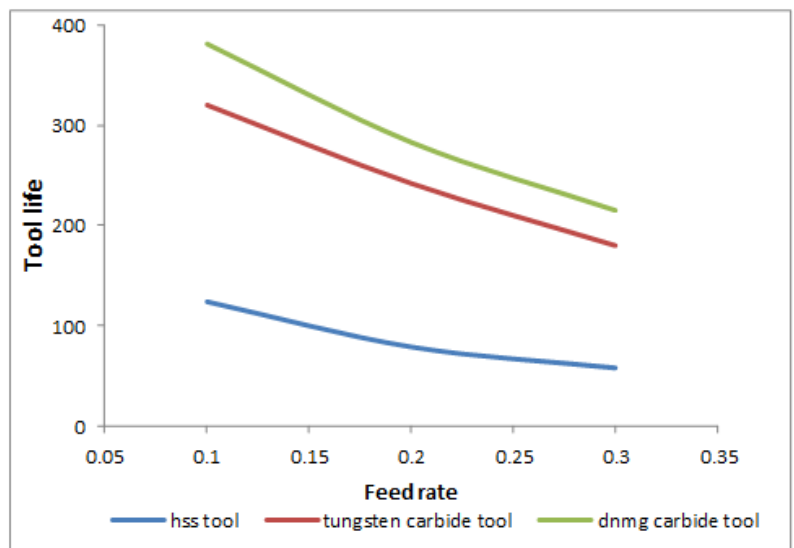

Figure 6c. Effect of feed on tool life at constant spindle speed of 1400 $\mathrm{rev} / \mathrm{min}$
Figure 7 show the effect of depth of cut $(0.5,1.0,1.5 \mathrm{~mm})$ on life of tools for all values of the spindle speed $(900,1120$, $1400 \mathrm{~mm} / \mathrm{rev}$ ). As the depth of cut increased from 0.5 to $1.5 \mathrm{~mm}$, the tool life of HSS reduced from $321 \mathrm{~s}$ to $224 \mathrm{~s}$ at constant spindle speed $900 \mathrm{rev} / \mathrm{min}$. The same trend was observed at spindle speed of $1120 \mathrm{rev} / \mathrm{min}$, as the depth of cut increased from $0.5 \mathrm{~mm}$ to $1.5 \mathrm{~mm}$ the contact length of the cutting edge with the workpiece increased and wear occurs deeper along the cutting edge as the tool life of HSS reduced from $220 \mathrm{~s}$ to $128 \mathrm{~s}$. At spindle speed of $1400 \mathrm{rev} / \mathrm{min}$, increased depth of cut up to $1.5 \mathrm{~mm}$ led to a corresponding increase in chip width and the center of pressure of the chip on the tool face moves away from the tool nose, causing a decreased in the tool life of HSS from 124 s to 58 s by $53 \%$ reduction. When using tungsten carbide tool it was observed that at constant spindle speed of $900 \mathrm{rev} / \mathrm{min}$ the tool life of tungsten carbide decreased from 726 s to $541 \mathrm{~s}$ as the depth of cut varied from $0.5 \mathrm{~mm}$ to $1.5 \mathrm{~mm}$ showing $25 \%$ reduction in tool life. At a spindle speed of $1120 \mathrm{rev} / \mathrm{min}$, there was a decreased in the tool life of tungsten carbide from $498 \mathrm{~s}$ to 356 s i.e. $29 \%$ reduction as the depth of cut vary from $0.5 \mathrm{~mm}$ to $1.5 \mathrm{~mm}$. The same trend was observed at constant spindle speed of $1400 \mathrm{rev} / \mathrm{min}$, increased depth of cut up to $1.5 \mathrm{~mm}$ caused more compressive stress on the cutting edge resulting in rapid fracture of the tool thereby reducing the life from $320 \mathrm{~s}$ to $180 \mathrm{~s}$. At these conditions, the effect of depth of cut at $1.5 \mathrm{~mm}$ was evident on tool life giving shorter tool life in all cases. However, this phenomenon can be attributed to the fact that increased depth of cut reduced tool life but actually increased the amount of material that could be removed by the tool. When using DMNG tool at a varying depth of cut the percentage reduction of the tool is lower compare to other tool materials. The tool life of DMNG at constant spindle speed of $900 \mathrm{rev} / \mathrm{min}$ decreased from $864 \mathrm{~s}$ to $644 \mathrm{~s}$ as the depth of cut increased from $0.5 \mathrm{~mm}$ to $1.5 \mathrm{~mm}$ i.e. $25 \%$ reduction. As the spindle speed increased to $1120 \mathrm{rev} / \mathrm{min}$ under the same conditions, lower values of tool life (594s to 424 s) were obtained i.e. $29 \%$ reduction. The same trend was observed at constant spindle speed of $1400 \mathrm{rev} / \mathrm{min}$, the tool life of DMNG decreased from 381s to $215 \mathrm{~s}$ as the depth of cut varying from $0.5 \mathrm{~mm}$ to $1.5 \mathrm{~mm}$. This happened because varying the depth of cut at high level aggravates tool wear which will excessively lead to shorter tool life.

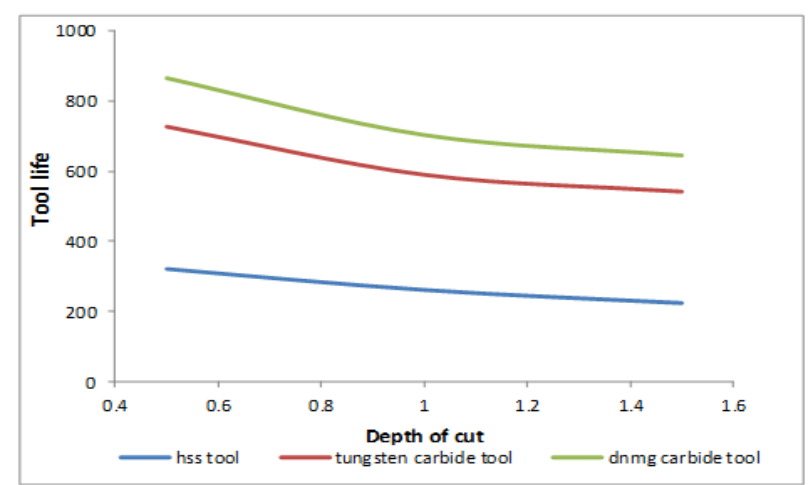

Figure 7a. Effect of depth of cut on life of tools at constant spindle speed of $900 \mathrm{rev} / \mathrm{min}$ 


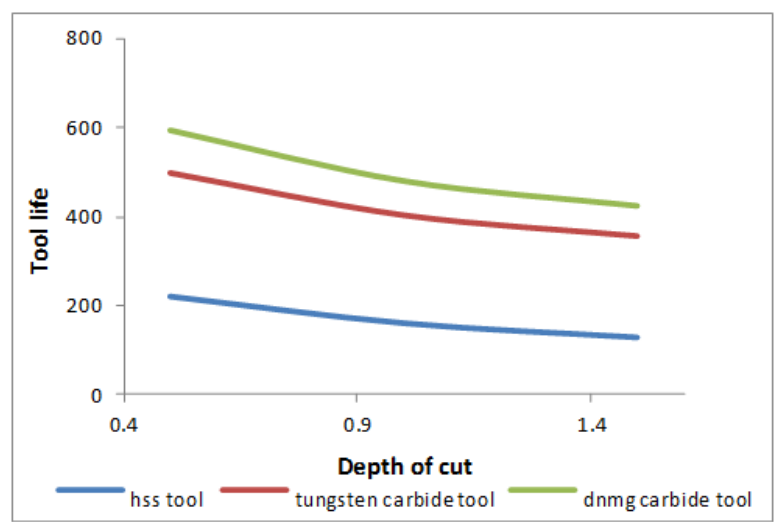

Figure 7b. Effect of depth of cut on life of tool at constant spindle speed of $1120 \mathrm{rev} / \mathrm{min}$

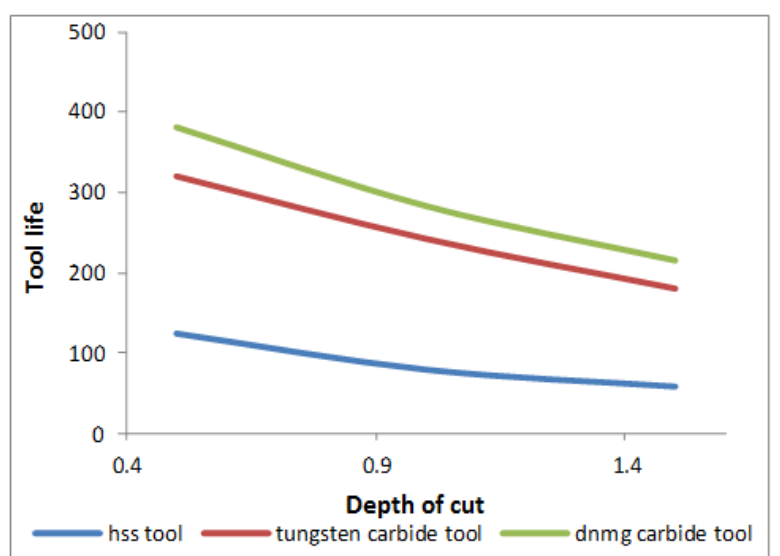

Figure 7c. Effect of depth of cut on life of tools at constant spindle speed of $1400 \mathrm{rev} / \mathrm{min}$

\subsection{Brass}

Figure 8 show the effect of spindle speed $(900,1120,1400$ $\mathrm{rev} / \mathrm{min})$ on life of tools for all values of the feed rate $(0.1$, $0.2,0.3 \mathrm{~mm} / \mathrm{rev}$ ). At spindle speed of 900 $\mathrm{rev} / \mathrm{min}$ and feed rate of $0.1 \mathrm{~mm} / \mathrm{rev}$, the tool life of HSS obtained was $386 \mathrm{~s}$ (Table 2) which indicate longer tool life, this agrees with [26] that the life of tools is very long while machining with low cutting parameters. As the spindle speed increased to $1400 \mathrm{rev} / \mathrm{min}$ under the same conditions, the tool life of HSS reduced by $56 \%$. The same decreasing trend was observed, as the spindle speed increased from $900 \mathrm{rev} / \mathrm{min}$ to $1400 \mathrm{rev} / \mathrm{min}$ at constant feed of $0.2 \mathrm{~mm} / \mathrm{rev}$, a brittle fracture occurs at the cutting edge rather than a gradual flank wear and the depth of the cracks on the cutting edge increased rapidly resulting in a catastrophic failure of the tool. At 0.3 $\mathrm{mm} / \mathrm{rev}$ feed rate, the tool life of HSS tool decreased dramatically from $279 \mathrm{~s}$ to $94 \mathrm{~s}$ with approximating $66 \%$ reduction as the spindle speed increased, this agrees with the results of Alauddin et al [27]. The same trends occur when using tungsten carbide tool. When the spindle speed was increased from $900 \mathrm{rev} / \mathrm{min}$ to $1400 \mathrm{rev} / \mathrm{min}$ for all values of the feed rate $(0.1,0.2,0.3 \mathrm{~mm} / \mathrm{rev})$, the tool life of tungsten carbide decreased. At constant feed of $0.1 \mathrm{~mm} / \mathrm{rev}$ the tool life of tungsten carbide decreased from 1028 s to 387 s i.e. $62 \%$ reduction. When spindle speed was increased at constant feed of $0.2 \mathrm{~mm} / \mathrm{rev}$ the tool life of tungsten carbide decreased from 760 s to 289 s i.e. $61 \%$ reduction. This is because cutting force on the tool edge increases as the spindle speed increased. Though carbide tools have high hot hardness and wear resistance, they have low fracture toughness. As a result tool wear intensifies at a high cutting speed. The same trend was observed when feed rate is constant at $0.3 \mathrm{~mm} / \mathrm{rev}$, tool life of tungsten carbide decreased from $746 \mathrm{~s}$ to $274 \mathrm{~s}$ as the spindle speed increased. This is as a result of increase in the spindle speed which caused vibration in the system leading to shorter tool life. When using DMNG tool at varying speeds, the percentage reduction of the tool was lower compare to other tool materials. As the spindle speed increased from $900 \mathrm{rev} / \mathrm{min}$ to $1400 \mathrm{rev} / \mathrm{min}$ at constant feed of $0.1 \mathrm{~mm} / \mathrm{rev}$, the tool life decreased from 1183 s to 440 s i.e. $62 \%$ reduction. The same trend occurred when feed was constant at $0.2 \mathrm{~mm} / \mathrm{rev}$, tool life of DMNG decreased from $867 \mathrm{~s}$ to $329 \mathrm{~s}$ as the spindle speed increased from $900 \mathrm{rev} / \mathrm{min}$ to $1400 \mathrm{rev} / \mathrm{min}$. Also at constant feed rate of $0.3 \mathrm{~mm} / \mathrm{rev}$ the tool life decreased from $848 \mathrm{~s}$ to $311 \mathrm{~s}$ as the spindle speeds varied from $900 \mathrm{rev} / \mathrm{min}$ to $1400 \mathrm{rev} / \mathrm{min}$. Varying the spindle speed at high level aggravates tool wear which will excessively lead to shorter tool life.

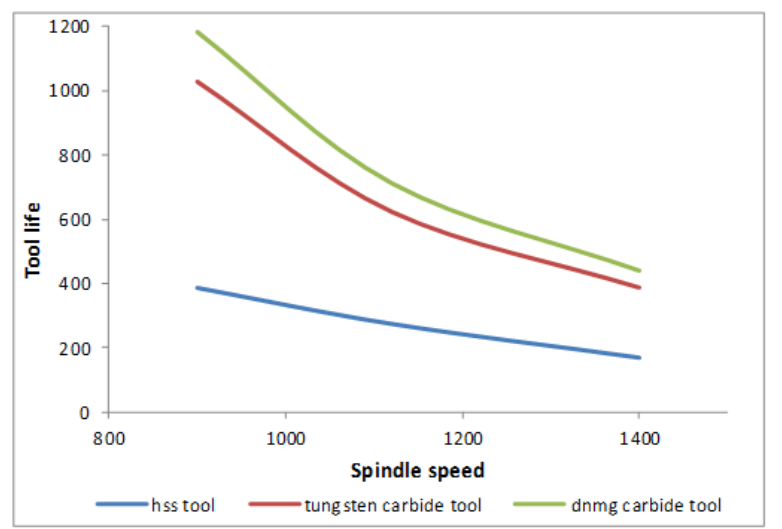

Figure 8a. Effect of spindle speed on life of tools at constant feed rate of 0.1 $\mathrm{mm} / \mathrm{rev}$

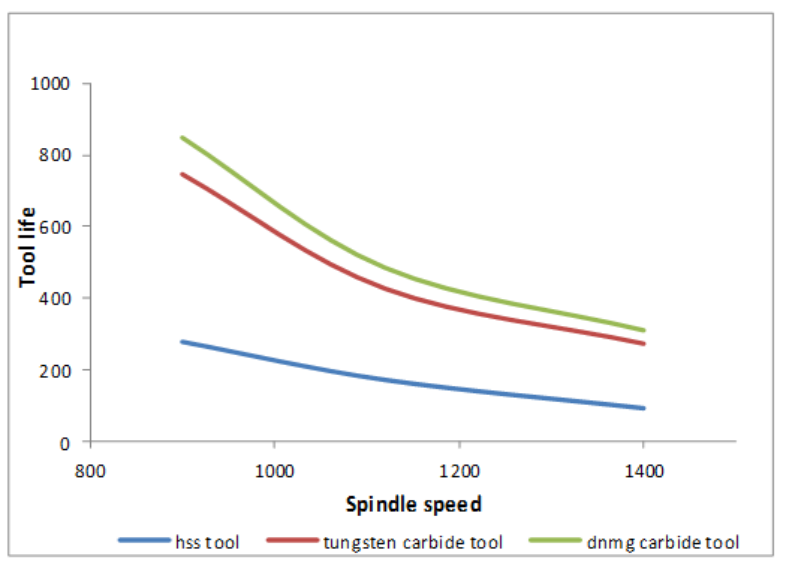

Figure 8b. Effect of spindle speed on life of tools at constant feed rate of 0.2 $\mathrm{mm} / \mathrm{rev}$ 


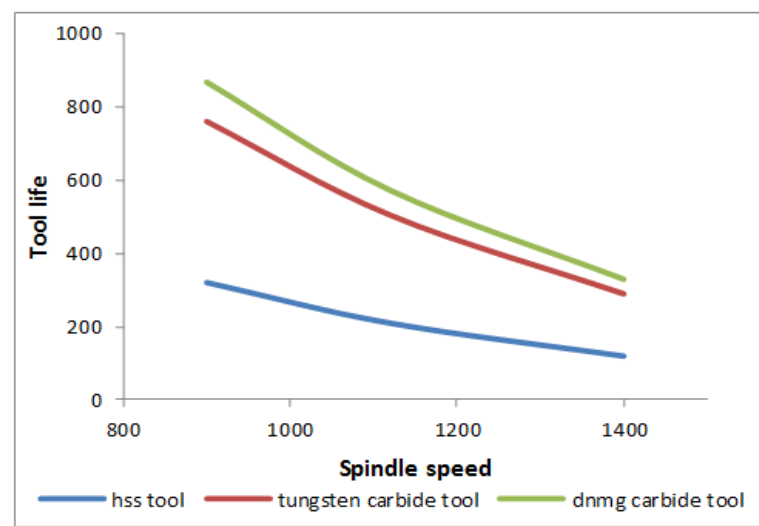

Figure 8c. Effect of spindle speed on life of tools at constant feed rate of 0.3 $\mathrm{mm} / \mathrm{rev}$

Figure 9 show the effect of feed rate $(0.1,0.2,0.3 \mathrm{~mm} / \mathrm{rev})$ on life of tools for all values of the spindle speed $(900,1120$, $1400 \mathrm{rev} / \mathrm{min}$ ). At $0.1 \mathrm{~mm} / \mathrm{rev}$ feed rate and $900 \mathrm{rev} / \mathrm{min}$ spindle speed, tool life of HSS tool was 386s. When the feed was increased to $0.3 \mathrm{~mm} / \mathrm{rev}$ at the same spindle speed, the tool life of HSS reduced to 279s (Table 2). The same trend was observed at spindle speed of $1120 \mathrm{rev} / \mathrm{min}$, as the feed rate increased from $0.1 \mathrm{~mm} / \mathrm{rev}$ to $0.3 \mathrm{~mm} / \mathrm{rev}$. The tool life of HSS reduced from 274 s to 173 s i.e. $36 \%$. It can be seen that percentage reduction in the HSS tool life increased from $28 \%$ to $36 \%$ which can be traced to the fact that increased feed rate led to a corresponding change in temperature, leading to shorter tool life. Tool wear was affected by temperature; the higher temperature the greater the tool wears. This agrees with Lin [28] that the wear is related to cutting temperature. The decreasing in tool life trend occurs due to more wear on the cutting edge at higher spindle speed of $1400 \mathrm{rev} / \mathrm{min}$. As the feed rate increased to $0.3 \mathrm{~mm} / \mathrm{rev}$, the tool life of HSS decreased from 169 s to 94 s i.e. by $44 \%$. When using tungsten carbide tool it was observed that at constant spindle speed of $900 \mathrm{rev} / \mathrm{min}$, the tool life of tungsten carbide decreased from $1028 \mathrm{~s}$ to $746 \mathrm{~s}$ as the feed varied from $0.1 \mathrm{~mm} / \mathrm{rev}$ to $0.3 \mathrm{~mm} / \mathrm{rev}$. At a spindle speed of $1120 \mathrm{rev} / \mathrm{min}$, the tool life of tungsten carbide decreased from $623 \mathrm{~s}$ to $427 \mathrm{~s}$ i.e. $31 \%$ reduction. This is similar to the result of Gorczyca [23] that, if the cutting speed and depth of cut are both constant, then the tool life decreased as the feed is increased. The same trend was observed at constant spindle speed of $1400 \mathrm{rev} / \mathrm{min}$, as the feed rate increased from $0.1 \mathrm{~mm} / \mathrm{rev}$ to $0.3 \mathrm{~mm} / \mathrm{rev}$. The tool life of tungsten carbide reduced from $387 \mathrm{~s}$ to $274 \mathrm{~s}$. At these conditions, the effect of feeding at $0.3 \mathrm{~mm} / \mathrm{rev}$ was evident on tool life resulting in shorter tool life in all cases. However, this phenomenon can be attributed to the fact that increased feed rate, reduced tool life but actually increased the amount of material that could be removed by the tool. The same trend was observed at constant spindle speed of $1400 \mathrm{rev} / \mathrm{min}$; the tool life of DMNG decreased from 440s to $311 \mathrm{~s}$ as the feed rate varied from $0.1 \mathrm{~mm} / \mathrm{rev}$ to $0.3 \mathrm{~mm} / \mathrm{rev}$. When using DMNG tool at a varying feed, the percentage reduction in the tool tool was lower compare to other tool materials. The tool life of DMNG at constant spindle speed of $900 \mathrm{rev} / \mathrm{min}$ decreased from $1183 \mathrm{~s}$ to $848 \mathrm{~s}$ as the feed rate increased from $0.1 \mathrm{~mm} / \mathrm{rev}$ to $0.3 \mathrm{~mm} / \mathrm{rev}$ i.e. $28 \%$ reduction. As the spindle speed increased to $1120 \mathrm{rev} / \mathrm{min}$ under the same conditions, lower values of tool life (712s to $485 \mathrm{~s})$ were obtained. This is similar to $307 \mathrm{~min}$ to $76 \mathrm{~min}$ obtained by Lin [28] at cutting speed of $66.88 \mathrm{~m} / \mathrm{min}$ and $94.2 \mathrm{~m} / \mathrm{min}$ for cemented low alloy steel using tungsten carbide high hardness cutting tool. The same trend was observed at constant spindle speed of 1400rev/min the tool life of DMNG decreased from 440s to $311 \mathrm{~s}$ as the feed rate vary from $0.1 \mathrm{~mm} / \mathrm{rev}$ to $0.3 \mathrm{~mm} / \mathrm{rev}$.

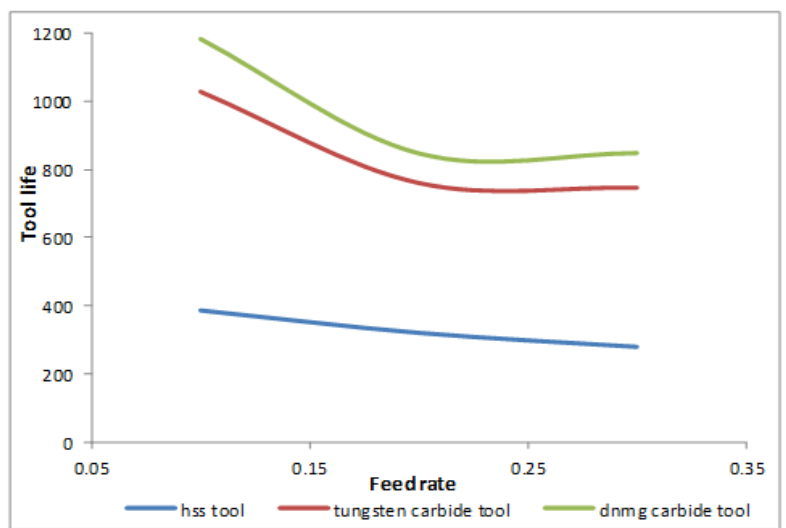

Figure 9a. Effect of feed rate on life of tools at constant spindle speed of $900 \mathrm{rev} / \mathrm{min}$

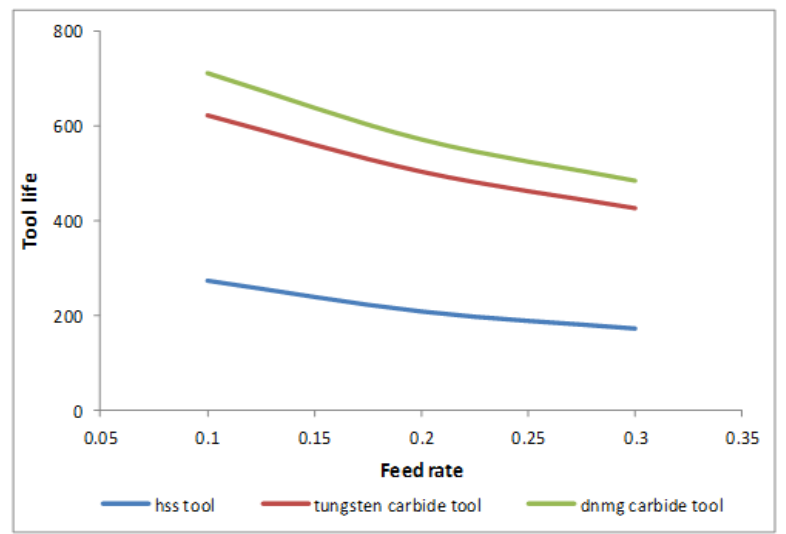

Figure 9b. Effect of feed rate on tool life at constant spindle speed of 1120 $\mathrm{rev} / \mathrm{min}$

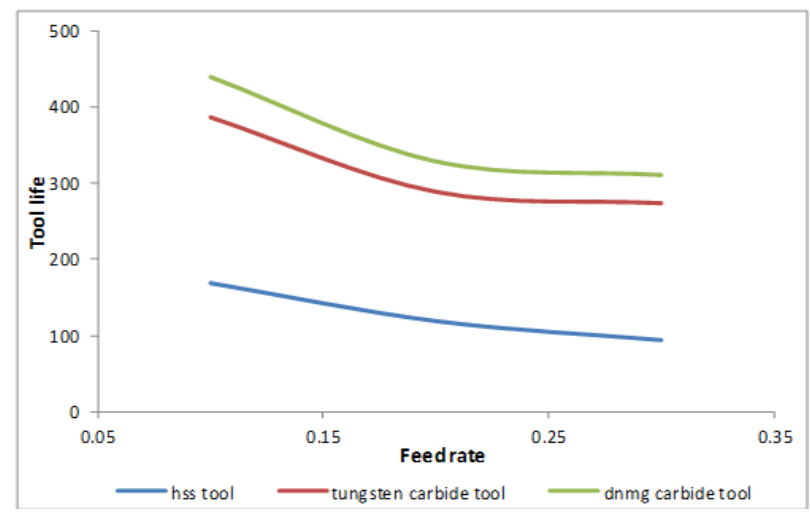

Figure 9c. Effect of feed rate on life of tools at constant spindle speed of $1400 \mathrm{rev} / \mathrm{min}$ 
Figure 10 show the effect of depth of cut $(0.5,1.0,1.5 \mathrm{~mm})$ on life of tools for all values of the spindle speed $(900,1120$, $1400 \mathrm{~mm} / \mathrm{rev}$ ). As the depth of cut increased from 0.5 to $1.5 \mathrm{~mm}$, the tool life of HSS is reduced from $386 \mathrm{~s}$ to $279 \mathrm{~s}$ at constant spindle speed of $900 \mathrm{rev} / \mathrm{min}$. The same trend was observed at $1120 \mathrm{rev} / \mathrm{min}$ spindle speed, as the depth of cut increased from $0.5 \mathrm{~mm}$ to $1.5 \mathrm{~mm}$ the contact length of the cutting edge with the workpiece increased and wear occurs deeper along the cutting edge as the tool life of HSS reduced from $274 \mathrm{~s}$ to $173 \mathrm{~s}$. At spindle speed of $1400 \mathrm{rev} / \mathrm{min}$, increased depth of cut up to $1.5 \mathrm{~mm}$ led to a corresponding increase in chip width and the center of pressure of the chip on the tool face moves away from the tool nose, causing a decreased in the tool life of HSS from 169 s to 94 s i.e. $44 \%$ reduction. When using tungsten carbide tool it was observed that at constant spindle speed of $900 \mathrm{rev} / \mathrm{min}$ the tool life decreased from $1028 \mathrm{~s}$ to $746 \mathrm{~s}$ as the depth of cut varied from $0.5 \mathrm{~mm}$ to $1.5 \mathrm{~mm}$ showing $27 \%$ reduction in tool life. At a spindle speed of $1120 \mathrm{rev} / \mathrm{min}$, there was a decrease in the tool life of tungsten carbide from $623 \mathrm{~s}$ to $427 \mathrm{~s}$ as the depth of cut vary from $0.5 \mathrm{~mm}$ to $1.5 \mathrm{~mm}$. The same trend was observed at constant spindle speed of $1400 \mathrm{rev} / \mathrm{min}$, increased depth of cut up to $1.5 \mathrm{~mm}$ caused more compressive stress on the cutting edge resulting in rapid fracture of the tool leading to decreased tool life from $387 \mathrm{~s}$ to 274 s i.e. $29 \%$ reduction. At these conditions, the effect of depth of cut at $1.5 \mathrm{~mm}$ was evident on tool life giving shorter tool life in all cases. This can be attributed to the fact that increased depth of cut reduced tool life. When using DMNG tool at a varying depth of cut the percentage reduction of the tool is lower compare to other tool materials. The tool life of DMNG at constant spindle speed of $900 \mathrm{rev} / \mathrm{min}$ decreased from $1183 \mathrm{~s}$ to $848 \mathrm{~s}$ as the depth of cut increased from $0.5 \mathrm{~mm}$ to $1.5 \mathrm{~mm}$ i.e. $28 \%$ reduction. As the spindle speed increased to $1120 \mathrm{rev} / \mathrm{min}$ under the same conditions, lower values of tool life ( $712 \mathrm{~s}$ to $848 \mathrm{~s})$ were obtained. The same trend was observed at constant spindle speed of $1400 \mathrm{rev} / \mathrm{min}$; the tool life of DMNG decreased from 440 s to $311 \mathrm{~s}$ as the depth of cut varied from $0.5 \mathrm{~mm}$ to $1.5 \mathrm{~mm}$.

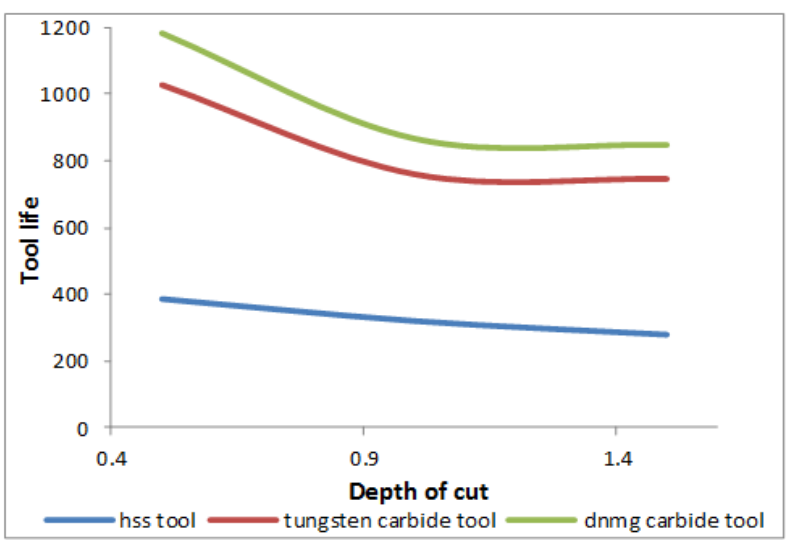

Figure 10a. Effect of depth of cut on life of tools at constant spindle speed of $900 \mathrm{rev} / \mathrm{min}$

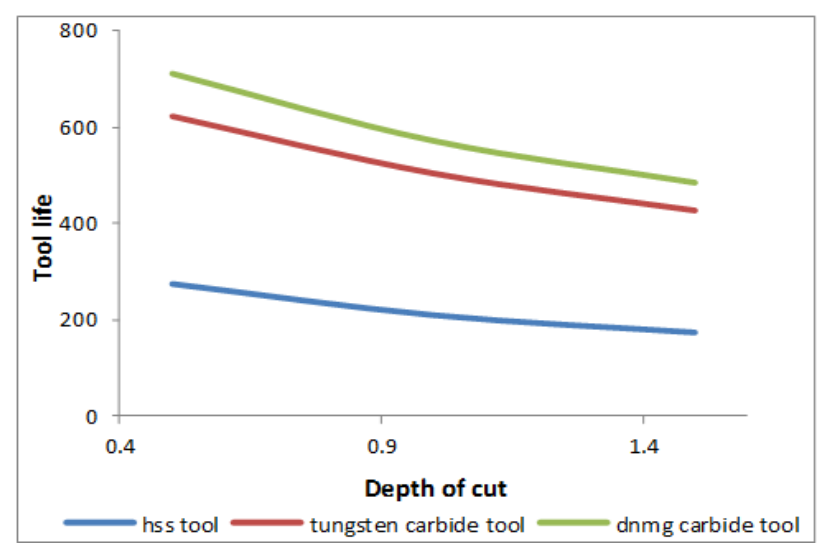

Figure 10b. Effect of depth of cut on life of tools at constant spindle speed of $1120 \mathrm{rev} / \mathrm{min}$

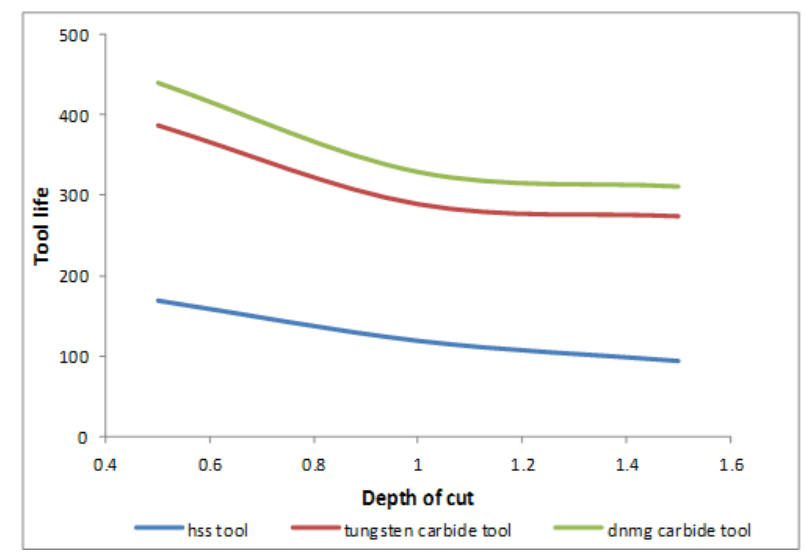

Figure 10c. Effect of depth of cut on life of tools at constant spindle speed of $1400 \mathrm{rev} / \mathrm{min}$

\subsection{Multiple Regression Modeling}

A mathematical model was developed to predict the tool life by relating it with process parameters. The spindle speed, feed rate and interaction between spindle speed and feed rate were considered in the development of the model. The significance level for the models was set at 0.05 . The correlation between factors (spindle speed, feed rate and interaction between spindle speed and feed rate) and tool life on the different tools and work materials were obtained by multiple linear regressions. MATLAB software package was used to obtain the generalised model of the form:

$$
\mathrm{T}_{\mathrm{L}}=\mathrm{C}+\beta_{1} * \mathrm{~N}+\beta_{2} * \mathrm{f}+\beta_{3} * \mathrm{~N} * \mathrm{f}
$$

Where, $\mathrm{T}_{\mathrm{L}}$ is tool life response; $f$ is feed rate in $\mathrm{mm} / \mathrm{rev}$; and $\mathrm{N}$ is spindle speed in rev/min.

In multiple linear regression analysis, $\mathrm{R}^{2}$ is the regression coefficient for the models, the magnitude of $\mathrm{R}$ indicates whether the regression provide accurate prediction of the criterion variables.

Using medium carbon steel as the work material, the multiple linear regression models of the three tool material were: 
$\mathrm{T}_{\mathrm{L}(\mathrm{HSS})}=394.5941-0.23434 * \mathrm{~N}-434.533 * \mathrm{f}+0.173567 \mathrm{~N} * \mathrm{f}$

$\mathrm{T}_{\mathrm{L}(\mathrm{TC})}=1001.509-0.52569 * \mathrm{~N}-888.254 * \mathrm{f}+0.29379 * \mathrm{~N} * \mathrm{f}$

$\mathrm{T}_{\mathrm{L}(\mathrm{DNMG})}=1654.574-0.86746 * \mathrm{~N}-1657.05 * \mathrm{f}+0.620223 * \mathrm{~N} * \mathrm{f}(6)$

The multiple linear regression models of the three tool materials, using mild steel were:

$$
\begin{aligned}
& \mathrm{T}_{\mathrm{L}(\mathrm{HSS})}=742.9268-0.42362 * \mathrm{~N}-786.242 * \mathrm{f}+0.316879 * \mathrm{~N} * \mathrm{f} \\
& \mathrm{T}_{\mathrm{L}(\mathrm{TC})}=1522.443-0.8232 * \mathrm{~N}-1270.28 * \mathrm{f}+0.431529 * \mathrm{~N} * \mathrm{f}
\end{aligned}
$$

$\mathrm{T}_{\mathrm{L}(\mathrm{DNMG})}=1817.271-0.98442 * \mathrm{~N}-1518.45 * \mathrm{f}+0.706712 * \mathrm{~N} * \mathrm{f}(9)$

The multiple linear regression models of the three tool material, using brass were:

$$
\begin{gathered}
\mathrm{T}_{\mathrm{L}(\mathrm{HSS})}=847.9646-0.46391 * \mathrm{~N} 843.8 \mathrm{f}+0.326433 * \mathrm{~N} * \mathrm{f} \\
\mathrm{T}_{\mathrm{L}(\mathrm{TC})}=2326.698-1.37712 * \mathrm{~N}-2901.04 \mathrm{f}+1.680732 * \mathrm{~N} * \mathrm{f} \\
\mathrm{T}_{\mathrm{L}(\mathrm{DNMG})}=2697.187-1.60377 * \mathrm{~N}-3484.31 \mathrm{f}+2.046178 * \mathrm{~N} * \mathrm{f}
\end{gathered}
$$

\subsection{Determination of Cutting Parameters}

\subsubsection{Analysis of the Signal-to-Noise (S/N) Ratio}

In Taguchi method, the term signal represents the desirable value, and noise represents the undesirable value. Process parameters with the highest $\mathrm{S} / \mathrm{N}$ ratio always give the best quality with minimum variance [10]. The $\mathrm{S} / \mathrm{N}$ ratio for each parameter level was calculated by finding the average of $\mathrm{S} / \mathrm{N}$ ratios at the corresponding level. Tables 2 shows the response table for $\mathrm{S} / \mathrm{N}$ ratio of tool life for larger is better obtained for different parameter levels. The $\mathrm{S} / \mathrm{N}$ ratio used for this type of response is as reported by Taguchi and Konishi [30]. The $\mathrm{S} / \mathrm{N}$ ratio for the larger-the-better is:

$$
\begin{gathered}
\mathrm{S} / \mathrm{N}=-10 * \log (\text { mean square deviation }) \\
\mathrm{S} / \mathrm{N}=-10 \log _{10}\left(1 / \mathrm{n} \Sigma \mathrm{y}^{-2}\right)
\end{gathered}
$$

Where, $\mathrm{n}$ is the number of measurements in a trial/row, in this case, $\mathrm{n}=1$; and $\mathrm{y}$ is the measured value in a run/row. The $\mathrm{S} / \mathrm{N}$ ratio values are calculated by taking into consideration Eqn. 13. The Tool life values measured from the experiments and their corresponding $\mathrm{S} / \mathrm{N}$ ratio values are listed in Tables 2.

The analysis of $\mathrm{S} / \mathrm{N}$ ratio of tool life showed that the first factor that caused tool life to be great was cutting speed; having feed rate and depth of cut as secondary factors. After that, the analysis was made to determine suitable factor of each main factor from $\mathrm{S} / \mathrm{N}$ ratio as shown in Figures 11-13

\subsection{Main Effects Plot for S/N Ratios}

\subsubsection{Medium Carbon Steel}

The effect of process parameters (spindle speed, feed rate and depth of cut) on the life of tools (HSS, tungsten carbide and DMNG carbide), using medium carbon steel as the work material is shown in Figure 11. The life of the tools decreased with increasing spindle speed, feed rate and depth of cut. This result is in agreement with those presented by Coldwell et al [31]. From this, it was evident that the spindle speed is the most influential cutting parameter on tool life. Higher values of this parameter, as well as of feed rates and depths of cut have proved to be detrimental to tool life [9].

In the analysis of $\mathrm{S} / \mathrm{N}$ ratio factor level was selected to give maximum $\mathrm{S} / \mathrm{N}$ ratio as the most suitable factor level. The selection of the most suitable factor level from the graphs showed that, level of factor that causes tool life to be great occurred at spindle speed of $900 \mathrm{rev} / \mathrm{min}, 0.1 \mathrm{~mm} / \mathrm{rev}$ feed rate and $0.5 \mathrm{~mm}$ depth of cut.

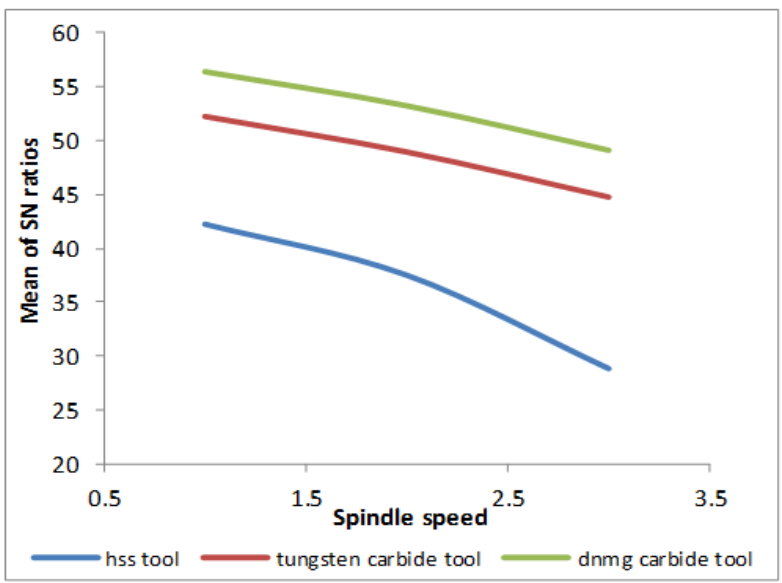

Figure 11a. Effect of spindle speed on life of tools

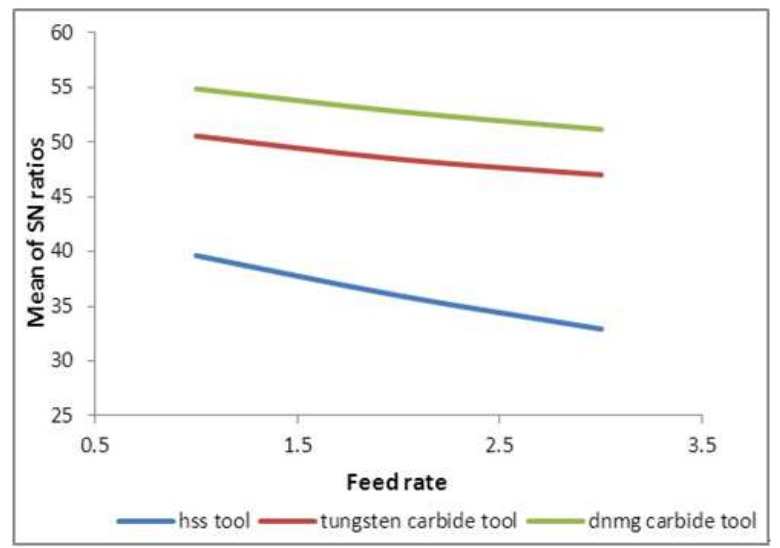

Figure 11b. Effect of feed rate on life of tools

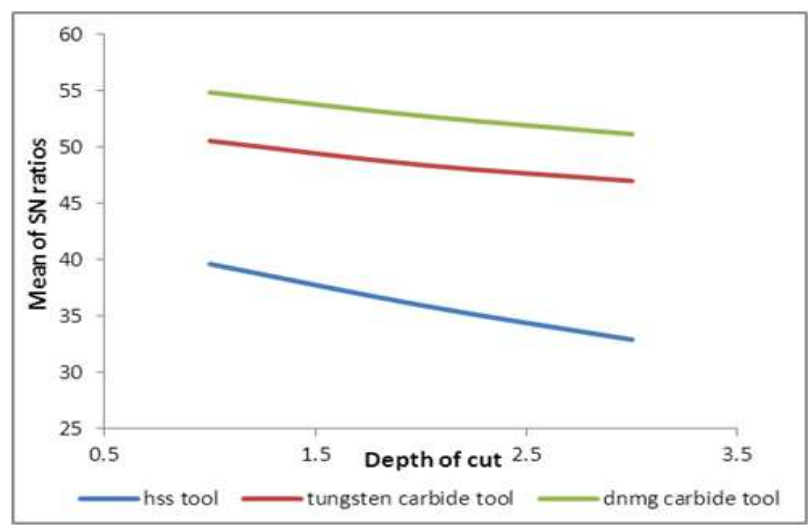

Figure 11c. Effect of depth of cut on life of tools 
Table 2a. Orthogonal array $L_{9}\left(3^{3}\right)$ design with measured Tool life for medium carbon steel

\begin{tabular}{|c|c|c|c|c|c|c|c|c|c|c|c|c|}
\hline \multirow{3}{*}{ No } & \multicolumn{3}{|c|}{ Factors } & \multirow{2}{*}{\multicolumn{3}{|c|}{ Parameters }} & \multirow{3}{*}{$\begin{array}{l}\text { HSS } \\
\text { Tool Life } \\
\text { (s) }\end{array}$} & \multirow{3}{*}{$\begin{array}{l}\text { S/N } \\
\text { Ratio } \\
\text { (db) }\end{array}$} & \multirow{3}{*}{$\begin{array}{l}\text { Tungsten } \\
\text { Carbide Tool } \\
\text { Life (s) }\end{array}$} & \multirow{3}{*}{$\begin{array}{l}\text { S/N } \\
\text { Ratio } \\
\text { (db) }\end{array}$} & \multirow{3}{*}{$\begin{array}{l}\text { DNMG } \\
\text { Carbide Tool } \\
\text { Life (s) }\end{array}$} & \multirow{3}{*}{$\begin{array}{l}\text { S/N } \\
\text { Ratio } \\
\text { (db) }\end{array}$} \\
\hline & $\mathbf{A}$ & B & D & & & & & & & & & \\
\hline & $\mathbf{N}$ & f & D & $\mathrm{N} \mathrm{rev/min}$ & f, mm/rev & d, $\mathbf{m m}$ & & & & & & \\
\hline 1 & 1 & 1 & 1 & 900 & 0.1 & 0.5 & 161 & 44.137 & 480 & 53.625 & 782 & 57.864 \\
\hline 2 & 2 & 2 & 2 & 1120 & 0.2 & 1.0 & 72 & 37.147 & 275 & 48.787 & 447 & 53.006 \\
\hline 3 & 3 & 3 & 3 & 1400 & 0.3 & 1.5 & 15 & 23.522 & 135 & 42.607 & 219 & 46.809 \\
\hline 4 & 3 & 1 & 1 & 1400 & 0.1 & 0.5 & 52 & 34.320 & 229 & 47.197 & 373 & 51.434 \\
\hline 5 & 1 & 2 & 2 & 900 & 0.2 & 1.0 & 128 & 42.144 & 400 & 52.041 & 650 & 56.258 \\
\hline 6 & 2 & 3 & 3 & 1120 & 0.3 & 1.5 & 54 & 34.648 & 233 & 47.347 & 379 & 51.573 \\
\hline 7 & 2 & 1 & 1 & 1120 & 0.1 & 0.5 & 105 & 40.424 & 348 & 50.832 & 580 & 55.269 \\
\hline 8 & 3 & 2 & 2 & 1400 & 0.2 & 1.0 & 27 & 28.627 & 167 & 44.454 & 284 & 49.066 \\
\hline 9 & 1 & 3 & 3 & 900 & 0.3 & 1.5 & 107 & 40.588 & 357 & 51.053 & 567 & 55.072 \\
\hline
\end{tabular}

Table 2b. Orthogonal array $L_{9}\left(3^{3}\right)$ design with measured Tool life for mild steel

\begin{tabular}{|c|c|c|c|c|c|c|c|c|c|c|c|c|}
\hline \multirow{3}{*}{ No } & \multicolumn{3}{|c|}{ Factors } & \multirow{2}{*}{\multicolumn{3}{|c|}{ Parameters }} & \multirow{3}{*}{$\begin{array}{l}\text { HSS } \\
\text { Tool } \\
\text { Life (s) }\end{array}$} & \multirow{3}{*}{$\begin{array}{l}\text { S/N } \\
\text { Ratio } \\
\text { (db) }\end{array}$} & \multirow{3}{*}{$\begin{array}{l}\text { Tungsten } \\
\text { Carbide Tool } \\
\text { Life (s) }\end{array}$} & \multirow{3}{*}{$\begin{array}{l}\text { S/N } \\
\text { Ratio } \\
\text { (db) }\end{array}$} & \multirow{3}{*}{$\begin{array}{l}\text { DNMG } \\
\text { Carbide Tool } \\
\text { Life (s) }\end{array}$} & \multirow{3}{*}{$\begin{array}{l}\mathrm{S} / \mathrm{N} \\
\text { Ratio } \\
\text { (db) }\end{array}$} \\
\hline & $\mathbf{A}$ & B & D & & & & & & & & & \\
\hline & $\mathbf{N}$ & $f$ & $d$ & $\mathrm{~N}$ rev/min & $f, \mathrm{~mm} / \mathrm{rev}$ & $d \mathrm{~mm}$ & & & & & & \\
\hline 1 & 1 & 1 & 1 & 900 & 0.1 & 0.5 & 321 & 50.130 & 726 & 57.219 & 864 & 58.730 \\
\hline 2 & 2 & 2 & 2 & 1120 & 0.2 & 1.0 & 160 & 44.082 & 403 & 52.106 & 480 & 53.625 \\
\hline 3 & 3 & 3 & 3 & 1400 & 0.3 & 1.5 & 58 & 35.269 & 180 & 45.105 & 215 & 46.649 \\
\hline 4 & 3 & 1 & 1 & 1400 & 0.1 & 0.5 & 124 & 41.868 & 320 & 50.103 & 381 & 51.618 \\
\hline 5 & 1 & 2 & 2 & 900 & 0.2 & 1.0 & 261 & 48.332 & 589 & 55.402 & 702 & 56.927 \\
\hline 6 & 2 & 3 & 3 & 1120 & 0.3 & 1.5 & 128 & 42.144 & 356 & 51.029 & 424 & 52.547 \\
\hline 7 & 2 & 1 & 1 & 1120 & 0.1 & 0.5 & 220 & 46.848 & 498 & 53.945 & 594 & 55.476 \\
\hline 8 & 3 & 2 & 2 & 1400 & 0.2 & 1.0 & 79 & 37.953 & 242 & 47.676 & 283 & 49.036 \\
\hline 9 & 1 & 3 & 3 & 900 & 0.3 & 1.5 & 224 & 47.001 & 541 & 54.664 & 644 & 56.178 \\
\hline
\end{tabular}

Table 2c. Orthogonal array $L_{9}\left(3^{3}\right)$ design with measured Tool life for brass

\begin{tabular}{|c|c|c|c|c|c|c|c|c|c|c|c|c|}
\hline \multirow{3}{*}{ No } & \multicolumn{3}{|c|}{ Factors } & \multirow{2}{*}{\multicolumn{3}{|c|}{ Parameters }} & \multirow{3}{*}{$\begin{array}{l}\text { HSS } \\
\text { Tool Life } \\
\text { (s) }\end{array}$} & \multirow{3}{*}{$\begin{array}{l}\mathrm{S} / \mathrm{N} \\
\text { Ratio } \\
\text { (db) }\end{array}$} & \multirow{3}{*}{$\begin{array}{l}\text { Tungsten } \\
\text { Carbide Tool } \\
\text { Life (sec) }\end{array}$} & \multirow{3}{*}{$\begin{array}{l}\text { S/N } \\
\text { Ratio } \\
\text { (db) }\end{array}$} & \multirow{3}{*}{$\begin{array}{l}\text { DNMG } \\
\text { Carbide Tool } \\
\text { Life (s) }\end{array}$} & \multirow{3}{*}{$\begin{array}{l}\text { S/N } \\
\text { Ratio } \\
\text { (db) }\end{array}$} \\
\hline & $\mathbf{A}$ & B & D & & & & & & & & & \\
\hline & $\mathbf{N}$ & $f$ & d & $\begin{array}{l}\mathrm{N} \\
\mathrm{rev} / \mathrm{min}\end{array}$ & $\begin{array}{l}f \\
\mathrm{~mm} / \mathrm{rev}\end{array}$ & $\begin{array}{l}d \\
\mathbf{m m}\end{array}$ & & & & & & \\
\hline 1 & 1 & 1 & 1 & 900 & 0.1 & 0.5 & 386 & 51.732 & 1028 & 60.240 & 1183 & 61.460 \\
\hline 2 & 2 & 2 & 2 & 1120 & 0.2 & 1.0 & 209 & 46.403 & 504 & 54.049 & 572 & 55.148 \\
\hline 3 & 3 & 3 & 3 & 1400 & 0.3 & 1.5 & 94 & 39.463 & 274 & 48.755 & 311 & 49.855 \\
\hline 4 & 3 & 1 & 1 & 1400 & 0.1 & 0.5 & 169 & 44.558 & 387 & 51.754 & 440 & 52.870 \\
\hline 5 & 1 & 2 & 2 & 900 & 0.2 & 1.0 & 320 & 50.103 & 760 & 57.616 & 867 & 58.760 \\
\hline 6 & 2 & 3 & 3 & 1120 & 0.3 & 1.5 & 173 & 44.761 & 427 & 52.609 & 485 & 53.715 \\
\hline 7 & 2 & 1 & 1 & 1120 & 0.1 & 0.5 & 274 & 48.755 & 623 & 55.890 & 712 & 57.050 \\
\hline 8 & 3 & 2 & 2 & 1400 & 0.2 & 1.0 & 119 & 41.511 & 289 & 49.218 & 329 & 50.344 \\
\hline 9 & 1 & 3 & 3 & 900 & 0.3 & 1.5 & 279 & 48.912 & 746 & 57.455 & 848 & 58.568 \\
\hline
\end{tabular}

\subsubsection{Mild Steel}

Figure 12 show the effect of process parameters on tool life using mild steel as the workpiece material. From the result it was observed that the higher the process parameters the lower the tool life. This is similar to the trend reported by Yamada et al [33] for AlTiN coated carbide end mills for hardened steel at high cutting parameters. From the analysis of the $\mathrm{S} / \mathrm{N}$ ratio, the optimum machining performance for the life of the tools was obtained at spindle speed of $900 \mathrm{rev} / \mathrm{min}$ (level 1), feed rate of $0.1 \mathrm{~mm} / \mathrm{min}$ (level 1) and $0.5 \mathrm{~mm}$ depth of cut (level 1). 


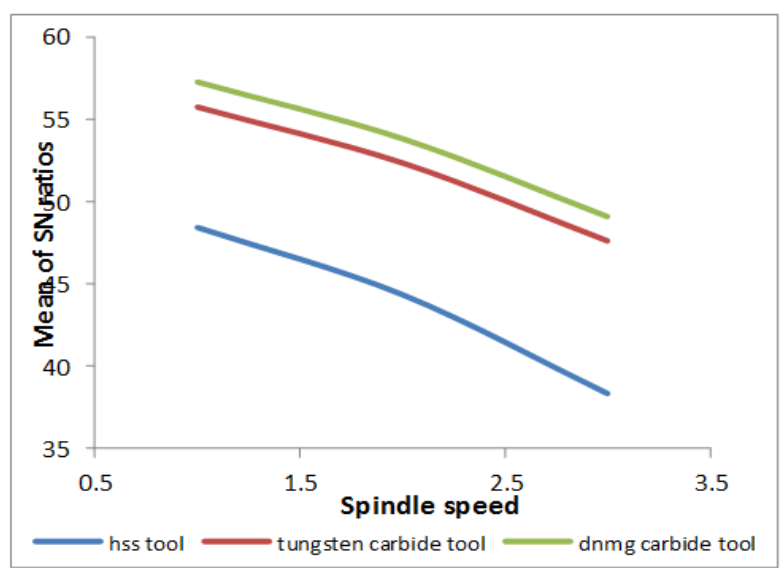

Figure 12a. Effect of spindle speed on life of tools

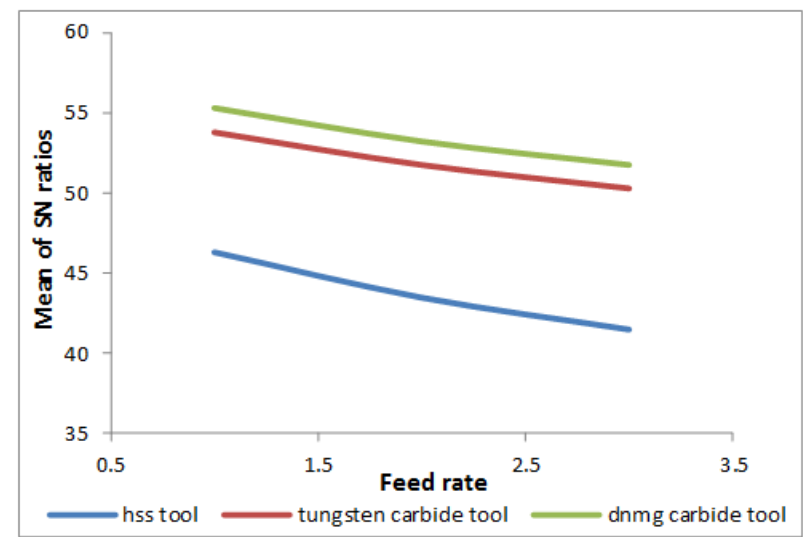

Figure 12b. Effect of feed rate on life of tools

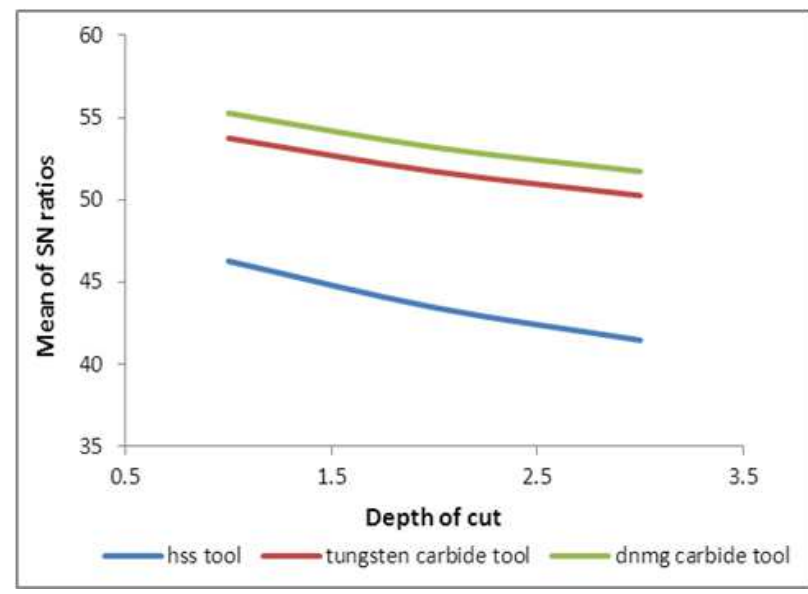

Figure 12c. Effect of depth of cut on life of tools

\subsubsection{Brass}

Figure 13 show the effect of process parameters on life of tools, using brass as the work material. The results revealed that the spindle speed, feed rate and depth of cut increased with decreasing tool life. This is in agreement with the results of Axinte and Dewes [34]. From the analysis of the $\mathrm{S} / \mathrm{N}$ ratio, the optimum conditions for tool life occurred when the level of spindle speed was $900 \mathrm{rev} / \mathrm{min}$, level of feed rate was $0.1 \mathrm{~mm} / \mathrm{rev}$ and the level of depth of cut was $0.5 \mathrm{~mm}$.

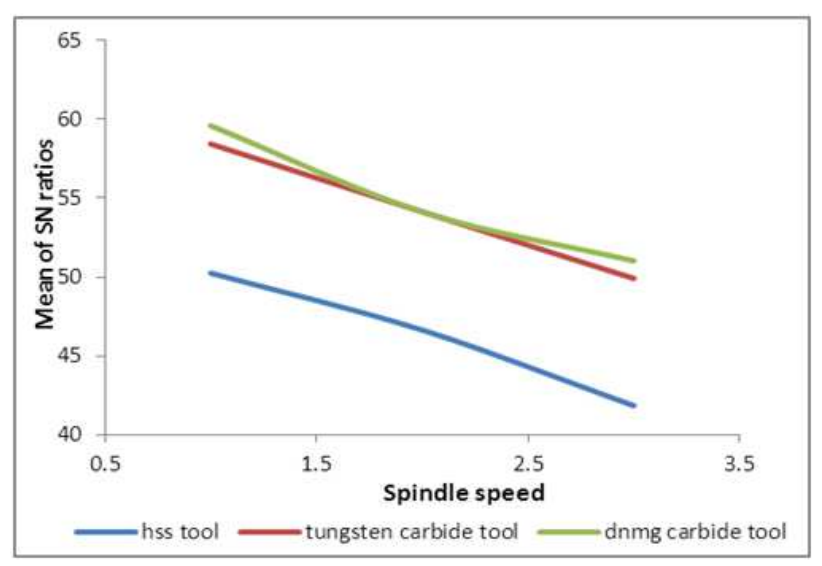

Figure 13a. Effect of spindle speed on life of tools

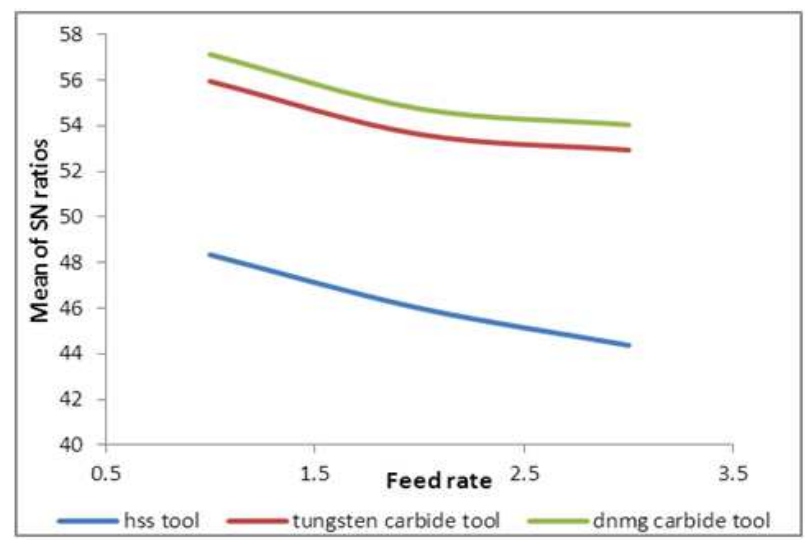

Figure 13b. Effect of feed rate on life of tools

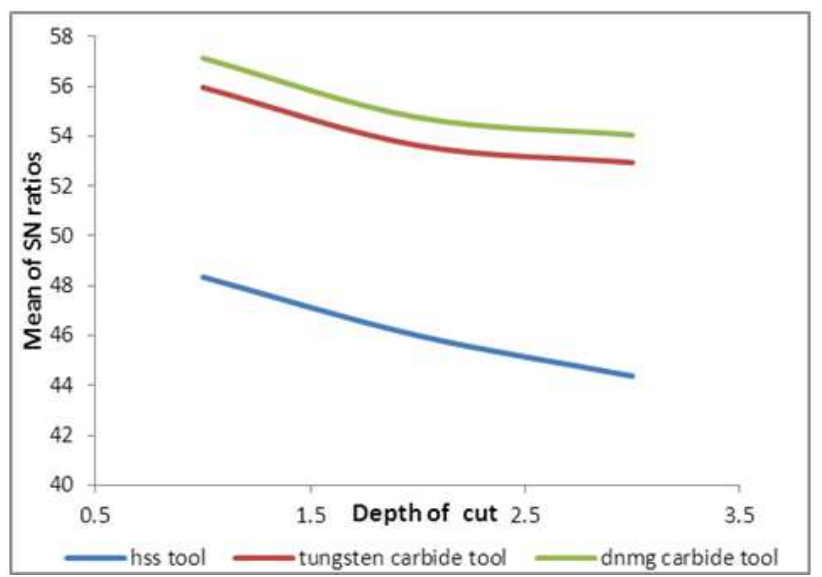

Figure 13c. Effect of depth of cut on life of tools

\subsection{Analysis of Variance}

The ANOVA was performed to investigate the statistical significance of the process parameters affecting the tool life. Analysis of Variance of the tool life (T) with the objective of the analyzing the influence of spindle speed $(\mathrm{N})$, feed rate $(f)$ and depth of cut $(d)$ on the total variance of the results was performed. The experiments were conducted for each combination of factors as per selected orthogonal array. Table 3 shows the results of the ANOVA with the tool life (T). This analysis was undertaken for a level of significance of $5 \%$, that is, for a level of confidence of $95 \%$. The last 
column of the tables indicates that the main effects are highly significant (all have very small $\mathrm{p}$-values).

From Table 3a, using medium carbon steel; it can be observed that the $p$-values of the spindle speed for HSS, tungten carbide and DMNG carbide are 0.0011, 0.0011 and 0.0006 respectively. The p-values of the feed rate for HSS, tungsten carbide and DMNG carbide are $0.0669,0.0873$ and 0.0407 respectively. While the feed rate $(p=0.0407)$ for DMNG carbide showed mild significant contribution on the tool life. But the interactions of spindle speed/feed rate $(\mathrm{p}=$ $0.3295)$ for HSS, $(p=0.4533)$ for tungsten carbide and $(p=$ 0.2878 ) for DMNG have no significant influence on tool life.

Table 3a. ANOVA results for tool life for the medium carbon steel HSS

\begin{tabular}{llllll}
\hline & Coeff & $\begin{array}{l}\text { Standard } \\
\text { Error }\end{array}$ & t Stat & P-value & Significance \\
\hline Intercept & 394.594 & 40.216 & 9.812 & 0.0002 & Significant \\
$\mathrm{N}$ & -0.234 & 0.035 & -6.749 & 0.0011 & Significant \\
$\mathrm{f}$ & -434.533 & 186.166 & -2.334 & 0.0669 & Not Significant \\
$\mathrm{N}^{*} \mathrm{f}$ & 0.174 & 0.161 & 1.080 & 0.3295 & Not Significant \\
\hline
\end{tabular}

TUNGSTEN CARBIDE

\begin{tabular}{llllll}
\hline & Coeff & $\begin{array}{l}\text { Standard } \\
\text { Error }\end{array}$ & t Stat & P-value & Significance \\
\hline Intercept & 1001.509 & 90.431 & 11.075 & 0.0001 & Significant \\
$\mathrm{N}$ & -0.526 & 0.078 & -6.733 & 0.0011 & Significant \\
$\mathrm{f}$ & -888.254 & 418.612 & -2.122 & 0.0873 & Not Significant \\
$\mathrm{N} * \mathrm{f}$ & 0.294 & 0.361 & 0.813 & 0.4533 & Not Significant \\
\hline
\end{tabular}

DNMG CARBIDE TOOL

\begin{tabular}{llllll}
\hline & Coeff & $\begin{array}{l}\text { Standard } \\
\text { Error }\end{array}$ & t Stat & P-value & Significance \\
\hline Intercept & 1654.574 & 130.510 & 12.67774 & 0.0001 & Significant \\
$\mathrm{N}$ & -0.868 & 0.113 & -7.69833 & 0.0006 & Significant \\
$\mathrm{f}$ & -1657.05 & 604.145 & -2.74281 & 0.0407 & Significant \\
$\mathrm{N}^{*} \mathrm{f}$ & 0.620 & 0.522 & 1.18904 & 0.2878 & Not Significant \\
\hline
\end{tabular}

From Table 3b, using mild steel as the work material, the spindle speed $(p=0.0012)$ for HSS, $(p=0.0015)$ for tungsten carbide and $(p=0.0013)$ for DMNG carbide have great influence on tool life. But the feed rate $(p=0.0693)$ for HSS, $(p=0.1279)$ for tungsten carbide and $(p=0.1227)$ for DMNG carbide have no significance influence on tool life. While the interaction of spindle speed/feed rate $(p=0.3310)$ for HSS, $(p=0.5053)$ for tungsten carbide and $(p=0.4956)$ for DMNG carbide have no effect on tool life.

Table 3b. ANOVA results for tool life for the mild steel

HSS

\begin{tabular}{llllll}
\hline & Coeff & $\begin{array}{l}\text { Standard } \\
\text { Error }\end{array}$ & t Stat & P-value & Significance \\
\hline Intercept & 742.927 & 73.664 & 10.085 & 0.0002 & Significant \\
$\mathrm{N}$ & -0.424 & 0.064 & -6.661 & 0.0012 & Significant \\
$\mathrm{f}$ & -786.242 & 340.999 & -2.306 & 0.0693 & Not Significant \\
$\mathrm{N}^{*} \mathrm{f}$ & 0.317 & 0.294 & 1.076 & 0.3310 & Not Significant \\
\hline
\end{tabular}

TUNGSTEN CARBIDE

\begin{tabular}{llllll}
\hline & Coeff & $\begin{array}{l}\text { Standard } \\
\text { Error }\end{array}$ & t Stat & P-value & Significance \\
\hline Intercept & 1522.443 & 150.515 & 10.115 & 0.0002 & Significant \\
$\mathrm{N}$ & -0.823 & 0.130 & -6.335 & 0.0015 & Significant \\
$\mathrm{f}$ & -1270.28 & 696.748 & -1.823 & 0.1279 & Not significant \\
$\mathrm{N}^{*} \mathrm{f}$ & 0.432 & 0.602 & 0.717 & 0.5053 & Not Significant \\
\hline
\end{tabular}

DNMG CARBIDE

\begin{tabular}{llllll}
\hline & Coeff & $\begin{array}{l}\text { Standard } \\
\text { Error }\end{array}$ & t Stat & P-value & Significance \\
\hline Intercept & 1817.271 & 176.822 & 10.277 & 0.0002 & Significant \\
$\mathrm{N}$ & -0.98445 & 0.153 & -6.448 & 0.0013 & Significant \\
$\mathrm{f}$ & -1518.45 & 818.526 & -1.855 & 0.1227 & Not Significant \\
$\mathrm{N}^{*} \mathrm{f}$ & 0.519108 & 0.707 & 0.735 & 0.4956 & Not Significant \\
\hline
\end{tabular}

From the Table $3 \mathrm{c}$, using brass as the workpiece material, it can be observed that the spindle speed $(p=0.0011)$ for HSS, $(p=0.0091)$ for tungsten carbide and $(p=0.0091)$ for DMNG carbide have great influence on tool life. The feed rate $(p=0.0703)$ for HSS and $(p=0.1658)$ for tungsten carbide and $(\mathrm{p}=0.1554)$ for DMNG carbide shows no significance contribution on the tool life. But the interactions of spindle speed/feed rate $(p=0.3512)$ for HSS, $(p=0.3261)$ for tungsten carbide and $(\mathrm{p}=0.3070)$ have no influence on tool life

Table 3c. ANOVA results for tool life for the brass

HSS

\begin{tabular}{llllll}
\hline & Coeff & $\begin{array}{l}\text { Standard } \\
\text { Error }\end{array}$ & t Stat & P-value & Significance \\
\hline Intercept & 847.9646 & 79.467 & 10.671 & 0.0001 & Significant \\
$\mathrm{N}$ & -0.46391 & 0.069 & -6.761 & 0.0011 & Significant \\
$\mathrm{f}$ & -843.8 & 367.860 & -2.294 & 0.0703 & Not Significant \\
$\mathrm{N} * \mathrm{f}$ & 0.326433 & 0.318 & 1.0278 & 0.3512 & Not Significant \\
\hline
\end{tabular}

TUNGSTEN CARBIDE

\begin{tabular}{llllll}
\hline & Coeff & $\begin{array}{l}\text { Standard } \\
\text { Errors }\end{array}$ & t Stat & P-value & Significance \\
\hline Intercept & 2326.698 & 386.412 & 6.021 & 0.0018 & Significant \\
$\mathrm{N}$ & -1.37712 & 0.334 & -4.128 & 0.0091 & Significant \\
$\mathrm{f}$ & -2901.04 & 1788.738 & -1.622 & 0.1658 & Not Significant \\
$\mathrm{N}^{*} \mathrm{f}$ & 1.680732 & 1.544 & 1.088 & 0.3261 & Not significant \\
\hline
\end{tabular}

DNMG CARBIDE

\begin{tabular}{llllll}
\hline & Coeff & $\begin{array}{l}\text { Standard } \\
\text { Error }\end{array}$ & t Stat & P-value & Significance \\
\hline Intercept & 2697.185 & 450.184 & 5.991 & 0.0019 & Significant \\
$\mathrm{N}$ & -1.604 & 0.3887 & -4.126 & 0.0091 & Significant \\
$\mathrm{f}$ & -3484.31 & 2083.946 & -1.672 & 0.1554 & Not Significant \\
$\mathrm{N} * \mathrm{f}$ & 2.046 & 1.799 & 1.137 & 0.3070 & Not Significant \\
\hline
\end{tabular}

\section{Conclusions}

The following conclusions can be drawn from this study:

Among the parameters which affect the process quality, spindle speed has an inverse influence on tool life and it was more dominant than the effect of feed rate

The effect of feed rate at $(0.3 \mathrm{~mm} / \mathrm{rev})$ was evident on tool life giving shorter tool life in all cases 
Using experimental data, a multiple linear regression model was developed and proves to be effective in optimizing the cutting condition in turning operations

In this study, the Taguchi method gives effective methodology in order to find out the effective performance output and machining conditions

DNMG carbide tool has the longest tool life among the three types of cutting tools followed by Tungsten carbide and HSS tool which leads to the conclusion that for improved tool life, lower cutting speeds should generally be selected in combination with suitable feed rates.

\section{Acknowledgements}

The authors wish to acknowledge the management of Godfrey Enginering Company, Lagos, Nigeria for making avaialble their facilities to carry out the experiments.

\section{References}

[1] N.A. Abukhshim, P.T. Mativenga and M.A. Sheikh, "Heat generation and temperature prediction in metal cutting," International Journal of Machine Tool and Manufacture, vol. 46, nos. 7-8, pp. 782-800, 2006.

[2] K. Musialek, "Role and importance of cutting fluids in high efficiency machining," The 2nd Seminar Workshop: Network Proceeding, Espoo- Otaniemi, Finland, March 1999.

[3] O. Tugrul and Y. Karpat, "Multi-objective optimization for turning processes using neural network modeling and dynamic neighborhood particle swarm optimization," International Journal Advance Manufacturing Technology, DOI 10.1007/s00170-006-0719-8, pp. 234-247, 2007.

[4] M. Kayhan and E. Budak, "An experimental investigation of chatter effects on tool life," Journal of Engineering Manufacture, vol. 223, no 11, pp. 1455-1463, 2009.

[5] V. Astakhov, "Effects of the cutting feed, depth of cut, and workpiece (bore) diameter on the tool wear rate," International Journal of Advanced Manufacturing Technology, DOI 10.1007/s00170-006-0635-y, 2006

[6] T.H. Mohammed, S.T. Montasser and B. Joachim, “ A study of the effects of machining parameters on the surface roughness in the end-milling process," Jordan Journal of Mechanical and Industrial Engineering, vol. 1, no 1, pp 1-5, 2007.

[7] T. Nadu, Tool life prediction based on cutting force and surface temperature in edge trimming of multidirectional CERP composites, Master of Science Thesis, Wichita State University, 2003.

[8] S.J. Ojolo, M.O.H. Amuda, O.Y. Ogunmola and C.U. Ononiwu, "Experimental determination of the effect of some straight biological oils on cutting force during cylindrical turning," Revista Materia, vol.13, pp. 650-663, 2008.

[9] K. Kadirgama, K.A. Abou-El-Hossein, B. Mohammad, M.M Noor and S.M. Sapuan, Prediction of tool life by statistic method in end-milling operation, Scientific Research and Essay, vol. 3, no 5, pp. 180, 2008.
[10] D.C. Montgomery, Design and analysis of experiments,Singapore: Wiley, 1991.

[11] S.R. Das, R.P. Nayak and D. Dhupal, "Optimization of cutting parameter on tool wear and workpiece surface temperature in turning of AISI D2 steel," International Journal of Lean Thinking, vol. 3, no 2, pp. 140-156, 2012.

[12] U. Miyachi, "Welding material control," Technical Ap plication Brief, pp. 1-5, 1999.

[13] T.R. Lin, "Experimental design and performance analysis of TiN-coated carbide tool in face milling stainless steel," Journal of Materials Processing Technology, vol. 127, pp. 1-7, 2002 .

[14] P.J. Ross, Taguchi techniques for quality engineering. Singapore: Mc Graw-Hill International, 1996.

[15] M. Nalbant, H. Gokkaya and G. Sur, "Application of Taguchi method in the optimization of cutting parameters for surface roughness in turning," Journal of Materials Processing Technology, vol. 28, pp. 1379-1385, 2007.

[16] W.H. Yang and Y.S. Tarng, "Design optimization of cutting parameters for turning operations based on the Taguchi method," Journal of Materials Processing Technology, vol. 34, pp. 122-129, 1998.

[17] S.S. Mahapatra, P. Patnaik and P.K. Patnaik, " Parametric analysis and optimization of cutting parameters for turning operations based on Taguchi Method," Proceedings of the International Conference on Global Manufacturing and Innovation, pp. 2-8, 2006.

[18] J.E. Kaye, D.H. Yan, N. Popplewell and S. Balakrishnan, "Predicting tool flank wear using spindle speed change," International Journal of Machine Tools and Manufacture, vol. 35, no. 9, pp. 1309-1320, 1995.

[19] A. Manna and S. Salodkar, "Optimization of machining conditions for effective turning of E0300 alloy steel," Journal of Materials Processing Technology, vol. 203, pp 147-153, 2008.

[20] P.S. Sivasakthivel, V.V. Murugan and R. Sudhakaran, "Prediction of tool wear from machining parameters by response surface methodology in end milling," International Journal of Engineering Science and Technology, vol. 2, no 6, pp. 1780-1789, 2010.

[21] M.S. Kartal, Investigation based on the Taguchi method for the surface roughness and tool life with $\mathrm{CNC}$ turning machine. M.Sc. Thesis, Marmara University, 2006.

[22] T. Tyan, Simulation and optimization for metal forming processes, cutting, rolling and extrusion. Ph.D. Thesis, University of Michigan, 1990

[23] F.E. Gorczyca, Application of metal cutting theory, New York: Industrial Press, 1987.

[24] Z.M. Zhou, Y.L. Zhang, J. Dong and X.Y. Li, "Effect of cutting parameters on diamond tool life during cutting stainless steel," Materials Science Forum, vol. 626-627, pp. 99-104, 2009

[25] P. Koshy, R.C. Dewes and D.K. Aspinwall, "High speed end milling of hardened AISI D2 tool steel (58HRC)," Journal of Material Processing Technology, vol. 127, pp. 266-273, 2002. 
[26] A.A. Khan, A.N.R. Zuraida and Y. Izayusmati, "High speed milling of cast iron and medium carbon steel using cemented and carbide tools," Proceeding of the BSME-ASME International Conference on Thermal Engineering, pp. 711-717, 2002

[27] M. Alauddin, M.A. El Baradie and M.S.J. Hashmi, "Prediction of tool life in end milling by response surface methodology," Journal of Materials Processing Technology, vol. 71, pp. 456-465, 1997.

[28] H.M. Lin, "Wear behavior in turning hardness alloy steel by CBN tool," Wear, vol. 264, pp. 679-684, 2008.

[29] O. Tugrul, K.H. Tsu and Z. Erol, "Effects of cutting edge geometry, work piece hardness, feed rate and cutting speed on surface roughness and forces in finish turning of hardened AISI H13 steel," International Journal Advanced Manufacturing Technology, vol. 25, pp. 262-269, 2005.

[30] G.H. Taguchi and S. Konishi, Taguchi methods orthogonal arrays and linear graphs, tools for quality engineering. Paperback, Students' Edition, 1987.
[31] H. Coldwell, R. Woods, M. Paul, P. Koshy, R.C. Dewes and D.K. Aspinwall. "Rapid machining of hardened AISI H13 and D2 moulds, dies and press tools," Journal of Material Processing Technology, vol. 135, pp. 301-311, 2003.

[32] K. Kadirgama, M.M. Noor, K.A. Abou-El-Hossein, H.H. Habeeb, M.M. Rahman, B. Mohamad R.A. and Bakar, "Effect of dry cutting on force and tool life when machining aerospace material," World academy of Science Engineering and Technology, vol.71, pp. 454-456, 2010

[33] Y. Yamada, T. Aoki, S. Kitaura, Y. Tanaka, Y. Okazaki and H. Hayasaki, "High speed cutting performance of (Al, Ti)N coated carbide end mills for hardened steels," Proc. first Int. French German Conf. High-Speed Machining, Metz, France, pp. 486-489, 1997.

[34] D.A. Axinte and R.C. Dewes, "Tool wear and workpiece surface integrity when high speed ball nose end milling hardened AISI H13," Proc. 3rd Int. Conf. Metal Cutting and HSM, Metz, France, pp. 171-179, 2001. 